\title{
De Paracas a Nasca: nuevas evidencias desde la vertiente oCCidental DE la SIERRA DE LuCANAS, AyaCuCHO
}

\author{
Markus Reindel ${ }^{\text {a }}$ \\ Johny Isla ${ }^{\mathrm{b}}$
}

\begin{abstract}
Resumen
Desde los primeros años de investigación, los paracas y nasca han sido consideradas como dos de las formaciones sociales más representativas de la costa sur peruana. Solo en las últimas fases del desarrollo Nasca se ha observado claros contactos con culturas de la sierra, especialmente con el estilo de cerámica característico del estado Wari que surgió cerca de la actual ciudad de Ayacucho, durante el Horizonte Medio. Sin embargo, trabajos de campo realizados en los últimos años en las cabeceras de los valles de Palpa, han puesto al descubierto numerosas evidencias de la ocupación Paracas y Nasca en la sierra. Estas nuevas evidencias nos obligan a reconsiderar conceptos tradicionales sobre los patrones de asentamiento y las estructuras socioeconómicas de los paracas y los nasca, incluyendo la época de transición entre ellas. Desde el 2006 los miembros del Proyecto Arqueologico Palpa-Lucanas han realizado intensos trabajos de campo en la parte norte de la cuenca del río Grande, especialmente en la parte alta de los valles de Palpa y Viscas. El registro de los asentamientos alcanzó hasta los puntos más altos de la vertiente occidental de los Andes, hasta una altura de 4300 metros sobre el nivel del mar. De este modo, el inventario de sitios arqueologicos en la vertiente occidental de los Andes, incluyendo aquellos de la costa, la yunga y la sierra, comprende ahora cerca de 1500 sitios pertenecientes a casi todos los periodos de tiempo. En este artículo presentamos los resultados de nuestras investigaciones en la sierra, poniendo énfasis en aquellos relacionados con los paracas y nasca, y en especial en la época de transición entre ambas, la cual muestra fuertes vinculos con la tradición Topará. Datos procedentes de las excavaciones en los sitios de Cutamalla y Huayuncalla aportan datos estratigráficos relevantes para el tema que se expone aqui.
\end{abstract}

Palabras claves: Paracas, Nasca, Topará, transición, rio Grande, valles de Palpa y Nasca.

\section{Abstract}

\section{From Paracas to Nasca: New evidence from the western slope of Lucanas highlands, Ayacucho}

Since the first investigations, the Paracas and Nasca have been considered as two of the most representative social formations of the Peruvian south coast. Elements indicating interaction with the highlands were identified only for the latest phases of the stylistic sequence of Nasca pottery, especially those related to the characteristic ceramic style of the Wari state that emerged near the modern city of Ayacucho, during the Middle Horizon. However, in the last years, fieldwork carried out in the Palpa valleys and its tributaries resulted in increasing evidence of Paracas and Nasca sites in the highlands. This new evidence forces us to reconsider our traditional concepts of Paracas and Nasca settlement patterns and socioeconomic structures, including the transitional epoch between them. Since 2006, members of the Palpa-Lucanas Archaeological Project conducted intensive fieldwork in the catchment area of the northern tributaries of the Nasca drainage, especially in the highest sections of the Palpa and Viscas valleys. The surveys reached up to the highest points of the western slope of

${ }^{a}$ KAAK: Comisión de Arqueología para Culturas No Europeas (KAAK) del Instituto de Arqueología Alemán (DAI) Correo electrónico: markus.reindel@dainst.de

b ANDES: Centro de Investigación para la Arqueología y el Desarrollo

Correo electrónico: isla.nasca@gmail.com 
the Andes, at an altitude of $4300 \mathrm{~m}$ above sea level. Thus, the inventory of the archaeological sites on the west side of the Andes, including coastal, yunga, and highlanders, now comprises about 1500 sites belonging almost to all time periods. In this paper we present the results of our studies in the highlands, emphasizing those related to the Paracas and Nasca, and especially to the transition between them, which shows strong relationships with the Topara tradition. Excavations on Cutamalla and Huayuncalla sites provide relevant stratigraphic data to the theme presented here.

Keywords: Paracas, Nasca, Topará, transitional, Rio Grande, Palpa and Nasca valleys.

\section{Introducción}

Desde los primeros años de investigación en la costa sur del Perú (Fig. 1), los paracas y los nasca han sido considerados como dos de las formaciones sociales más representativas de la región. Sin embargo, en el curso de los últimos años, los trabajos de campo en los valles de Palpa y sus tributarios nos han permitido registrar y documentar cada vez más evidencias de ambas sociedades en zonas ecológicas correspondientes a la yunga y a la sierra, hasta llegar a la puna misma, arriba de los $4000 \mathrm{msnm}$. Estas evidencias nos obligan a reconsiderar los conceptos tradicionales acerca de los patrones de asentamiento y de las estructuras socioeconómicas establecidas en esta parte de la costa y sierra sur del Perú.

Entre los años 2006 y 2011, en el marco de los Proyectos Arqueológicos Nasca-Palpa y PalpaLucanas (bajo la dirección de los autores) ${ }^{1}$, se han realizado intensos trabajos de campo en el área adyacente a los ríos tributarios de la parte norte de la cuenca del río Grande, especialmente en la parte alta correspondiente a los valles de Palpa y Viscas. El registro de los asentamientos y otros restos arqueológicos alcanzó sus puntos más altos en la cordillera occidental de los Andes, a una altura de $4350 \mathrm{msnm}$, donde el altiplano ayacuchano constituye una barrera natural que separa las cuencas de los ríos Grande y Pampas. De este modo, el inventario de sitios arqueológicos en el lado oeste de los Andes, incluyendo la costa (Palpa) y la sierra (en la parte oeste de Lucanas), comprende actualmente alrededor de 1500 sitios pertenecientes a todos los períodos de tiempo.

Como parte de las investigaciones en la sierra se ha realizado un completo registro de los asentamientos y otros rasgos arqueológicos, así como excavaciones en área en los sitios de Cutamalla y Huayuncalla y excavaciones restringidas en varios otros sitios ${ }^{2}$. En forma paralela a los estudios arqueológicos también se realizó un completo estudio del paleoclima, cuyos resultados nos ayudaron a conocer y entender mejor las condiciones del medio ambiente en tiempos prehispánicos (Eitel et al. 2005; Eitel y Mächtle 2009; Mächtle y Eitel 2013).

Debido a la casi total ausencia de estudios en la zona, el marco temporal para nuestros estudios en la sierra, especialmente para determinar la filiación cultural de los asentamientos y materiales asociados, estuvo basado en la clásica secuencia de cronología elaborada en la costa (Rowe 1967), la cual ha sido afinada en nuestro proyecto mediante intensas investigaciones en diversos sitios de los valles de Palpa (Unkel et al. 2007, 2012; Isla y Reindel en este volumen). Esta secuencia cronológica ha sido desarrollada en base a más de 150 fechados de radiocarbono que fueron obtenidos de muestras provenientes de excavaciones controladas realizadas en varios sitios de la costa. En este sentido y en relación con el tema que se presenta aquí, se puede decir con bastante confianza que el desarrollo de los paracas ocurrió entre los años 800 y 200 a.C., mientras que la transición de Paracas a Nasca está fechada entre los años 200 a.C. y 50 d.C. También se sabe que los Nasca se desarrollaron entre los años 50 y 650 d.C., al final del cual se observa la presencia de los wari en la región.

Durante los trabajos de prospección y excavación en la sierra, la filiación cronológica de los sitios fue asignada principalmente en base a la cerámica de superficie. Para la datación de las diferentes fases de desarrollo de los paracas y los nasca hemos utilizado fragmentos de cerámica diagnóstica, los cuales por su gran similitud con aquellos de la costa son fácilmente comparables con 


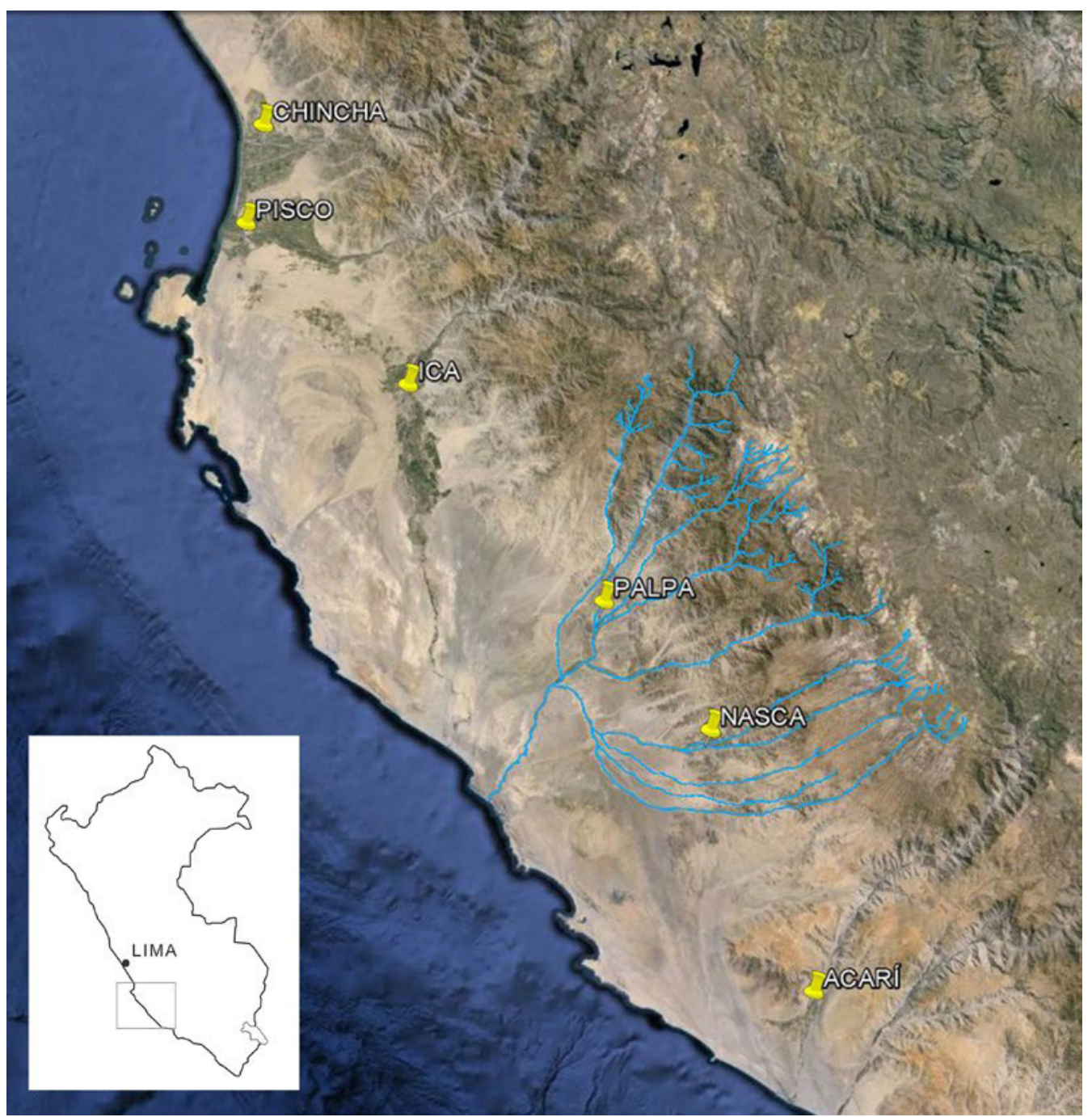

Figura 1. Mapa de la costa y sierra sur del Perú, con ubicación de los valles de Palpa y sus tributarios en la parte norte de la cuenca del río Grande (mapa editado por los autores).

las secuencias de cronología relativa vigentes para ambas sociedades (ver Rowe 1960; Menzel et al. 1964; Hecht 2009, 2013). En tal sentido, hemos realizado análisis detallados de la cerámica de la costa y la sierra para poder detectar alguna diferencia y en base a los análisis macroscópicos se puede decir que los rasgos diagnósticos de la cerámica de ambas zonas parecen ser los mismos. Solo en el caso de la cerámica de la época Nasca Medio (fases Nasca 4 y Nasca 5) de la sierra, se nota la inclusión de algunos elementos decorativos en el borde que no ocurren en la costa, lo que estaría indicando la existencia de una variante regional durante ese tiempo.

Por otro lado, debido a la mayor cantidad de vegetación arbustiva y a los pocos saqueos (huaqueos) ocurridos en los sitios de la sierra, resulta mucho más difícil encontrar materiales arqueológicos en la superficie de los sitios que en aquellos de la costa o yunga. Otra diferencia importante con los sitios de la costa y de la yunga es que en la sierra el porcentaje de cerámica fina y diagnóstica es escasa, lo cual en varios casos nos ha impedido definir con mayor certeza la filiación cronológica de los sitios. A partir de este hecho, es posible hacer algunas inferencias acerca de la estructura 
o composición de la gente - en este caso de los paracas y los nasca - que vivía en la sierra. Por un lado, es posible sugerir que en la sierra había un mayor porcentaje de población rural — campesinos y pastores-, que en la costa y por tanto había un menor consumo de productos finos y elaborados, o que el acceso a dichos productos en la sierra estaba más restringido a algunos grupos de mayor prestigio. Estas son hipótesis que se analizarán con mayor detalle en futuros trabajos de campo.

Dicho esto, en este artículo vamos a presentar brevemente los resultados de los estudios en la sierra, poniendo énfasis en la época de transición entre los paracas y nasca a partir de las evidencias arqueológicas documentadas en relación con ese lapso de tiempo.

\section{2. Área de investigación}

Luego de varios años de investigación en los valles de $\mathrm{Palpa}^{3}$, los cuales se desarrollaron especialmente en la costa, al pie de los Andes, a partir del año 2006 decidimos extender nuestras investigaciones hacia la parte alta de dichos valles, hasta llegar a la sierra y la puna misma, arriba de los $4300 \mathrm{msnm}$ (Fig. 2). Estas investigaciones se realizaron como parte de los estudios emprendidos en el marco del Proyecto Arqueológico Palpa-Lucanas, en los cuales, desde un inicio, se comprobó

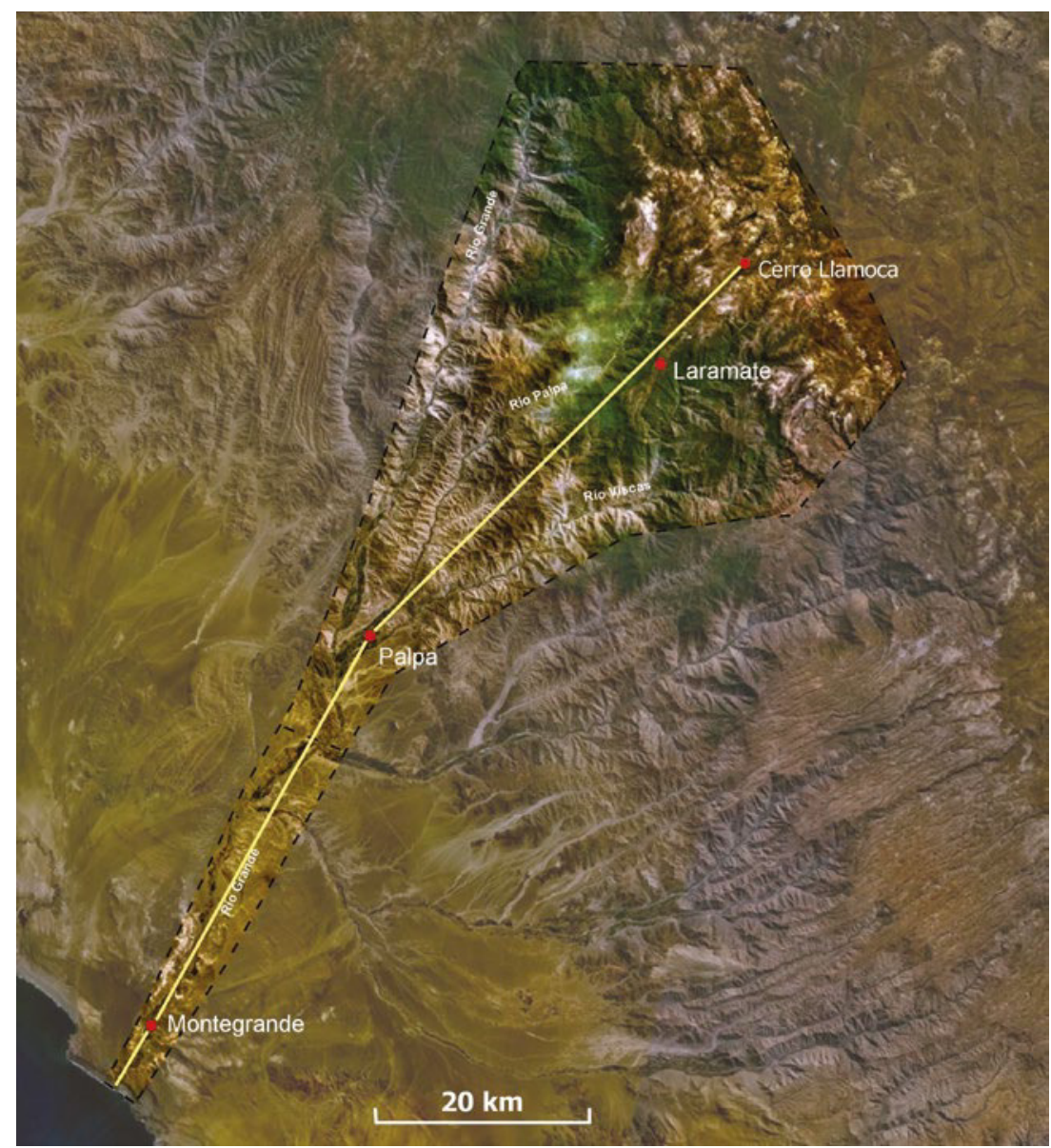

Figura 2. Foto satelital de la parte norte de la cuenca del río Grande donde se muestra el área de desarrollo del Proyecto Transecta Andina. La parte alta constituye el centro de las investigaciones del Proyecto Palpa-Lucanas (mapa elaborado por los autores). 
la presencia continua de asentamientos prehispánicos, de todos los tiempos, en la parte media-alta y alta de los valles de Palpa. Dichos asentamientos pertenecen a sociedades conocidas tradicionalmente como "costeńas», lo cual nos permite realizar un estudio más completo del proceso de asentamiento en esta parte de la costa y sierra sur del Perú.

Estos valles representan una situación típica en el área andina, la cual se caracteriza por la presencia de varios pisos ecológicos (costa, yunga — conocida también como yunga desértica-, sierra y puna) en una distancia relativamente corta, lo que facilita el acceso, la comunicación y el intercambio de productos en poco tiempo. Las evidencias arqueológicas indican que esta situación no es reciente, sino que se viene repitiendo desde hace mucho tiempo, al parecer, desde el establecimiento de las primeras poblaciones sedentarias en la región (Reindel e Isla 2013; Isla y Reindel 2017).

En este contexto, el área de investigación del Proyecto Palpa-Lucanas comprende a los tributarios septentrionales de la cuenca del río Grande, los cuales tienen su origen en la vertiente occidental de los Andes, a unos 4350 msnm, en la provincia de Lucanas, Ayacucho; desde donde atraviesan los diferentes pisos ecológicos - los oasis fluviales ubicados al pie de los Andes y la amplia franja del desierto costeño-, hasta desembocar en el océano Pacífico. En total se estima que entre la puna y el litoral hay una distancia de unos 100 kilómetros lineales. Las investigaciones se desarrollaron específicamente en la sección correspondiente a la parte alta de los valles de Palpa y Viscas, la cual está integrada por los ríos Llauta, Laramate y Ocaña. El área central de los estudios se encuentra en el distrito de Laramate, donde el río del mismo nombre conforma el eje principal de la zona de investigación, cuyos límites por el norte y sur se encuentran alrededor de los poblados de Llauta y Ocaña, respectivamente ${ }^{4}$. Esta zona, conocida también como «las cabezadas», se encuentra entre los 2000 y 4300 msnm.

En general se trata de una zona bastante accidentada, cuya topografía está caracterizada por la presencia de cerros altos con pendientes muy inclinadas, colinas, lomas y espolones, crestas y farallones rocosos. Las zonas aptas para la vida humana y, en especial, para el desarrollo de la agricultura, son escasas y se concentran en la parte baja de los cerros, en las quebradas y en bordes aluviales de los ríos principales y sus tributarios. Esto es especialmente notable alrededor de los poblados de Llauta, Laramate y Ocaña, así como en los alrededores del caserío de Locchas y Armaycancha. Por otro lado, la amplia llanura que se encuentra entre los ríos Llauta y Laramate, así como los cerros que se encuentran arriba de los $3800 \mathrm{msnm}$, están cubiertos de pastos estacionales que son apropiados para el desarrollo de la ganadería estable y permanente. En este contexto, las actividades de la mayoría de los habitantes de esta parte de la sierra ayacuchana se relacionan con la producción de bienes primarios, los cuales mayormente se llevan a la costa para su intercambio y comercio.

\section{Los estudios arqueológicos}

Desde los primeros trabajos de campo, la zona de investigación demostró que tenía un gran potencial para los estudios arqueológicos (Reindel 2010, 2012). Así, lo primero que se notó fue la presencia de un importante número de asentamientos prehispánicos pertenecientes casi a todas las épocas y períodos de tiempo (Fig. 3), los cuales en muchos casos conforman centros poblados bastante grandes.

Además de los asentamientos, tanto en la sierra como en la puna, destaca la presencia de dos tipos de restos arqueológicos que tuvieron gran importancia en la economía de las poblaciones asentadas en la zona, como también la tienen hasta hoy, pero en menor escala. Por un lado, una gran cantidad de terrazas agrícolas antiguas que se localizan cerca de los asentamientos, sobre todo cubriendo las laderas bajas de los cerros, en donde los grandes complejos de andenes conforman un extenso paisaje cultural (Fig. 4) y, por otro lado, los numerosos corrales antiguos localizados en alturas que están por encima de los $3800 \mathrm{msnm}$, los cuales muestran la gran importancia que tenía 


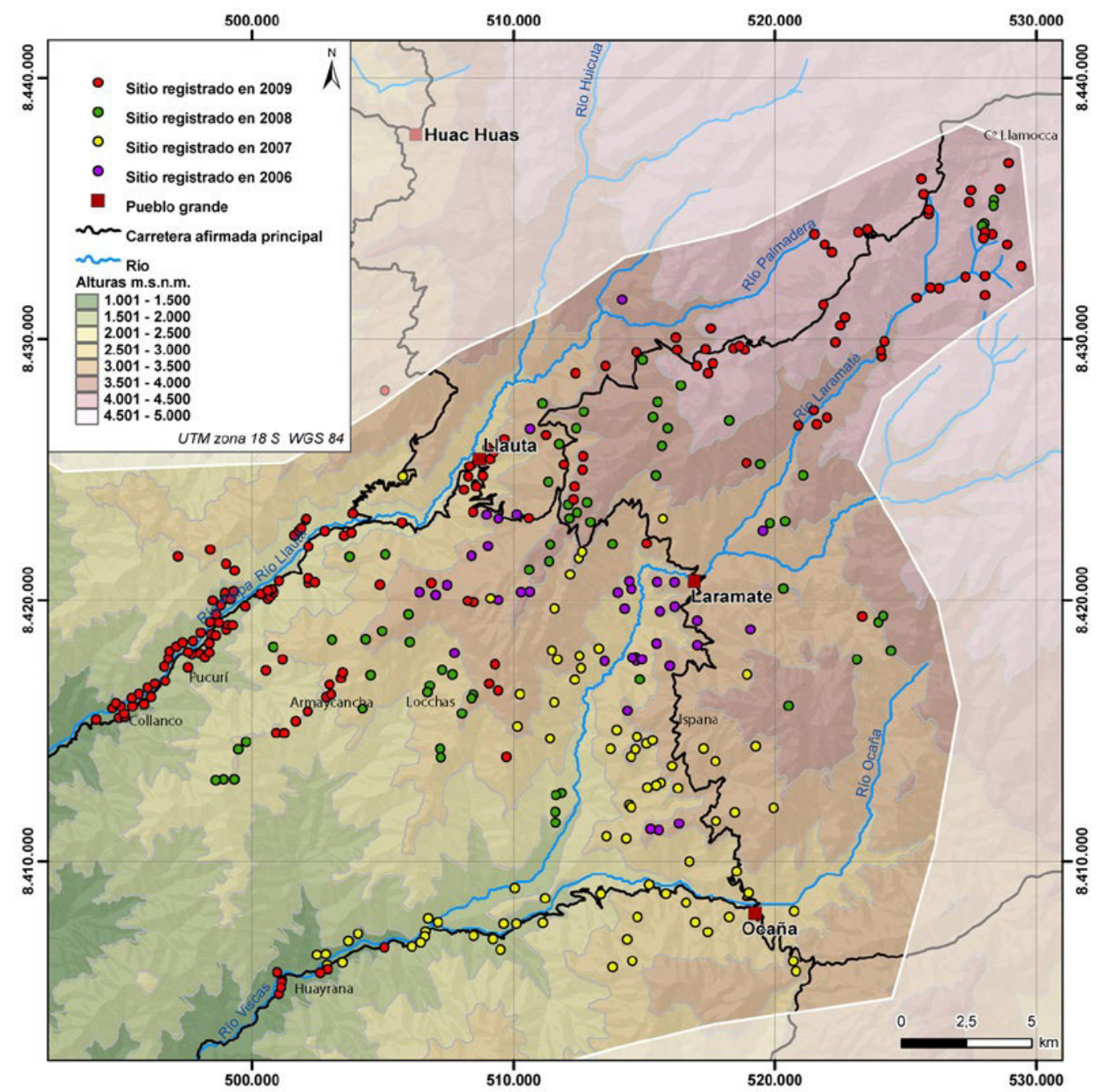

Figura 3. Mapa de la parte alta de los valles de Palpa, con ubicación de los sitios arqueológicos registrados en los trabajos de prospección realizados en la sierra. (mapa elaborado por los autores).

la crianza y el manejo de camélidos en tiempos prehispánicos (Fig. 5). En la actualidad solo una parte mínima de las terrazas de cultivo antiguas se utilizan para la agricultura, y lo mismo se puede decir de los corrales, la mayoría de los cuales están abandonados debido a la disminución de los rebaños, lo que viene a ser consecuencia directa de la cada vez más notable falta de lluvias y por ende a la escasez de pastos.

Teniendo en cuenta estos aspectos, los estudios arqueológicos en la sierra comprendieron prolongados e intensos trabajos de prospección arqueológica, en los que se hizo el registro y la documentación de la mayoría de restos arqueológicos visibles en la superficie. Asimismo, se realizaron excavaciones restringidas y excavaciones en área en varios sitios que fueron elegidos según objetivos específicos de la investigación. 


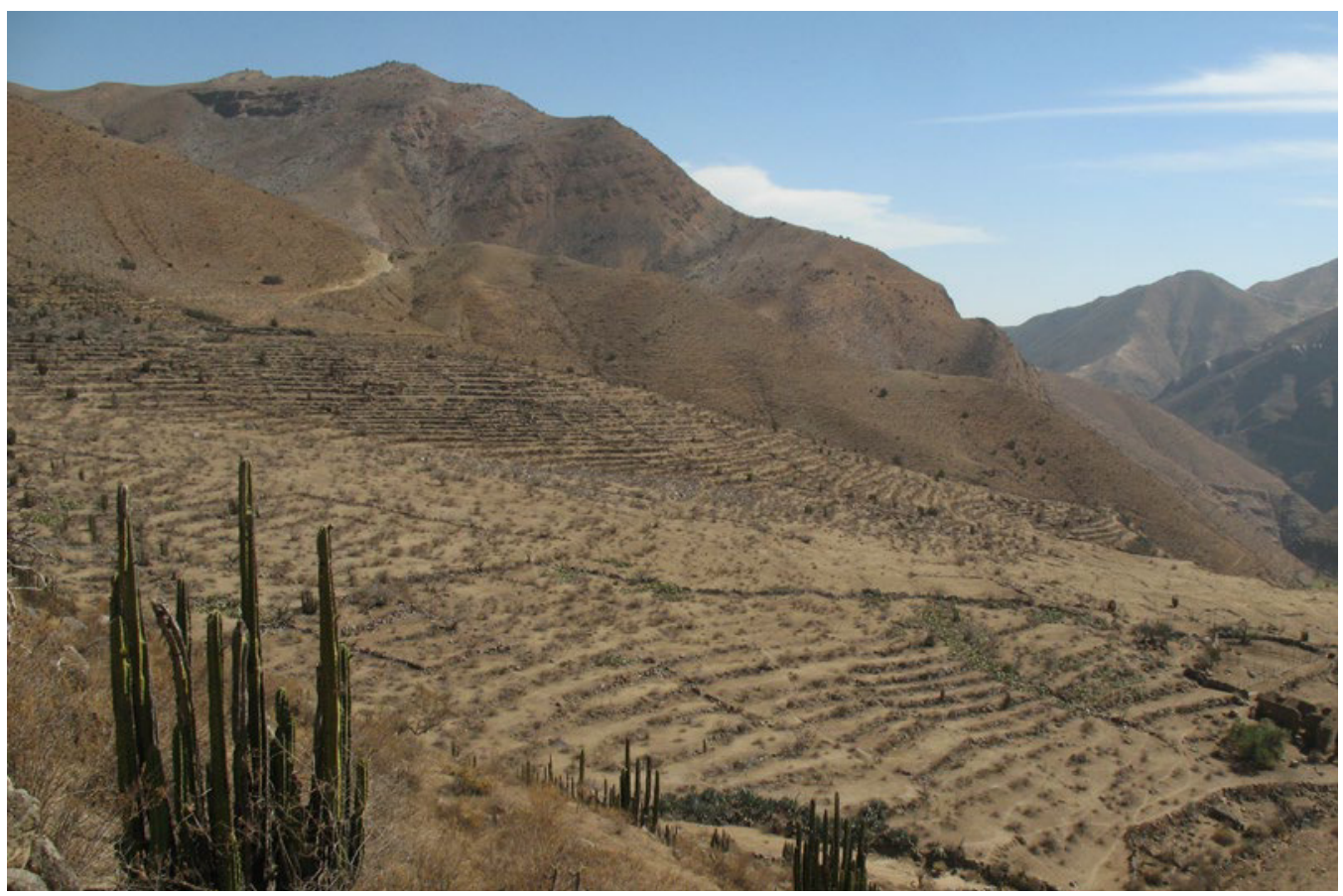

Figura 4. Vista de un inmenso complejo de terrazas agricolas localizadas en el sector de Santa Maria, en la margen izquierda del rio Laramate (foto Johny Isla).

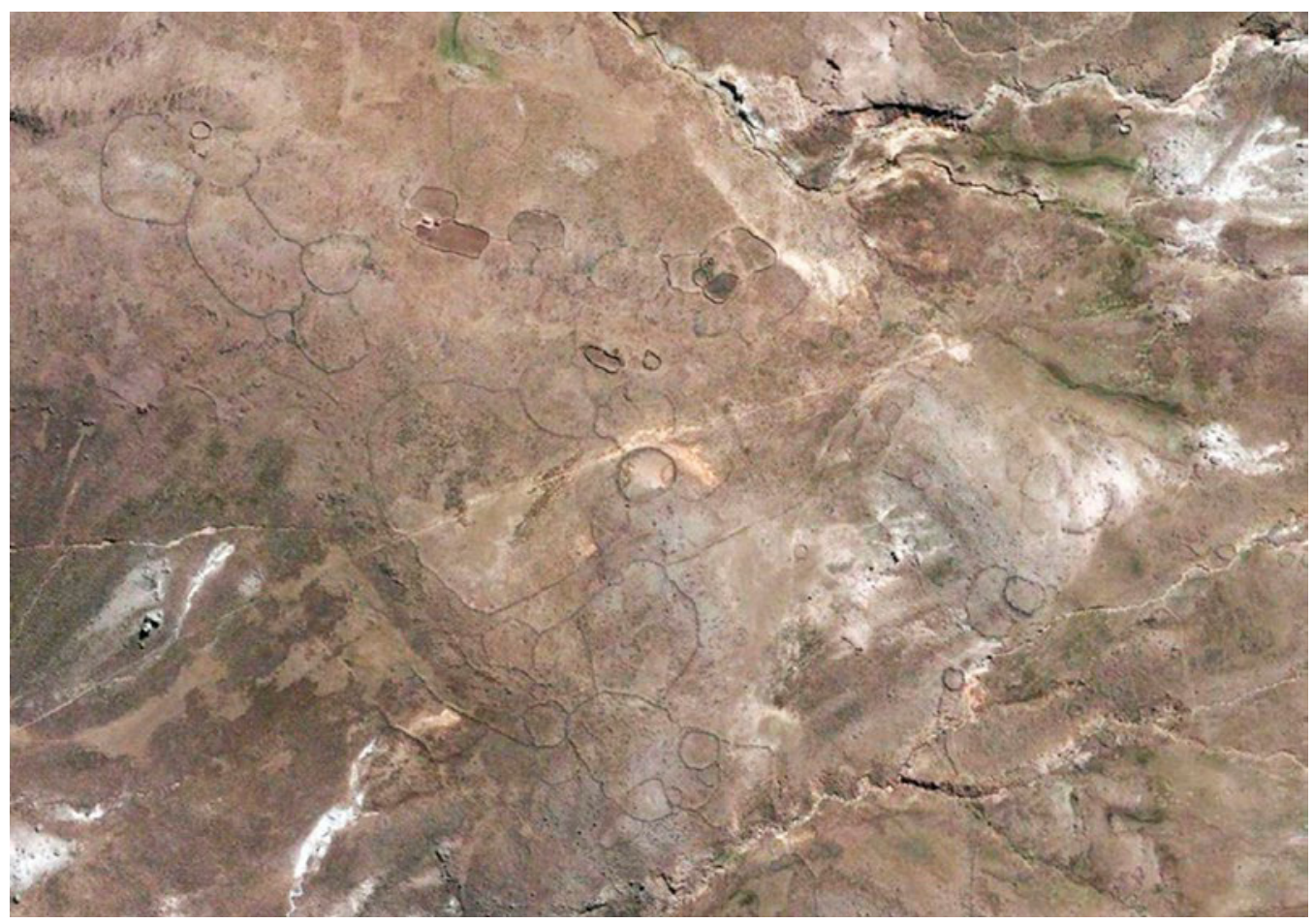

Figura 5. Foto satelital de la puna en el sector de Palmadera, valle de Atocata, en donde se puede ver numerosos corrales antiguos, algunos muy grandes. Nótese la ubicación cerca de algunos puquiales o afloramientos de agua (fuente Quickbird 2005). 


\section{Los trabajos de prospección}

Los trabajos de prospección arqueológica estuvieron a cargo de Carolina Hohmann y Johny Isla, quiénes junto a un grupo de arqueólogos y estudiantes hicieron recorridos a pie cubriendo casi todos los espacios accesibles en la zona estudiada. La prospección por el valle de Palpa (Llauta) empezó en el poblado de Pucurí y llegó hasta el poblado de Llauta y sus alrededores, mientras que por el valle de Viscas (Ocaña) empezó en el caserío de Huayrana y llegó hasta el poblado de Ocaña y sus alrededores. El área nuclear de los trabajos de prospección estaba alrededor del poblado de Laramate y en ambas márgenes del río del mismo nombre. En la parte más alta de la zona de estudio, la prospección llegó por el valle de Atocata hasta las nacientes del río Laramate, alcanzando la cima del cerro Llamocca alrededor de los $4350 \mathrm{msnm}$. De este modo, en cuatro temporadas de campo — de 2006 a 2009— se llegó a cubrir un área de más de 500 kilómetros cuadrados, los cuales se encuentran mayormente en la sierra y solo una parte en la puna.

Para diferenciar los sitios de la sierra de aquellos de la yunga y por ende de la costa, hemos fijado un límite variable entre los 1800 y $2000 \mathrm{msnm}$. Este límite parece coincidir bastante bien con ciertos rasgos geográficos y culturales. En efecto, a esa altura se observa un cambio en el paisaje agreste y seco que caracteriza la yunga desértica, por otro que muestra los cerros cubiertos de hierbas y pastos típicos de la sierra. Asimismo, alrededor de esa altitud se observa una disminución en el número de asentamientos y también una ubicación distinta de los mismos, debido a que los valles (mejor dicho, las quebradas), cuyos bordes fueron el foco de asentamiento en la costa y la yunga, a partir de esa altura son más angostos y normalmente presentan laderas empinadas. Por esta razón, los asentamientos ya no ocupan los bordes de los valles, sino las cimas de lomas y colinas que se encuentran cerca de las numerosas laderas y quebradas fértiles que, a su vez, conforman los tributarios de los principales ríos.

Durante los trabajos de prospección en la sierra hemos identificado y registrado más de 345 sitios arqueológicos pertenecientes a casi todos los períodos de tiempo (Fig. 3), aunque nuestra mayor atención estaba orientada hacia los sitios de las épocas Paracas y Nasca. En algunos sitios se ha registrado más de una ocupación, por lo cual el número total de sitios resulta siendo mayor que el número indicado líneas arriba. Como sitios arqueológicos se han considerado los lugares de vivienda (poblados, aldeas, caseríos), los corrales, las estructuras funerarias, los abrigos y otros rasgos menores de especial significado como altares o espacios rituales y petroglifos. Un caso especial lo constituyen las terrazas de cultivo, las cuales se encuentran mayormente entre los $1800 \mathrm{y}$ $3000 \mathrm{msnm}$, ocupando los bordes de las quebradas y laderas adyacentes, en zonas protegidas de los vientos y en donde las condiciones ambientales forman variados microclimas.

Debido a la escasez o falta de materiales diagnósticos en la superficie, en cerca del $20 \%$ del total de sitios no ha sido posible asignar ninguna época o período de tiempo. De esta forma, según nuestra base de datos, hasta el momento solo cuatro sitios pueden ser atribuidos al Período Inicial, 99 sitios a la época Paracas, nueve sitios a la época de transición de Paracas a Nasca, 67 sitios a diversas fases Nasca, 61 sitios a Wari, 119 sitios a Ica/Chincha y finalmente 24 sitios a los inka. En este punto es importante indicar que, salvo el descubrimiento de un abrigo de cazadores recolectores del período Lítico (8000 a.C.), localizado cerca del Cerro Llamocca, en la puna (Reindel e Isla 2013: 91), todavía no se conocen sitios tempranos — correspondientes a los períodos Arcaico y del Formativo Temprano- en la zona de investigación.

A primera vista, según la cantidad de sitios, los diferentes períodos de tiempo parecen tener una distribución casi equivalente. Sin embargo, debemos de tener en cuenta que estos datos no consideran el tamaño ni la densidad de construcciones presentes en cada uno de ellos. Asimismo, tampoco se ha considerado la duración de cada período de tiempo ni otros parámetros. Este análisis, que puede darnos una idea más clara de los patrones de asentamiento y de los cambios a lo largo del tiempo, puede ser consultado en la tesis de Volker Soßna (2015), quién hizo el análisis más detallado de esos aspectos. 
Figura 7. Mapa de la zona de investigación en la sierra, con ubicación de los sitios de filiación Nasca (gráfico elaborado por Volker Soßna).

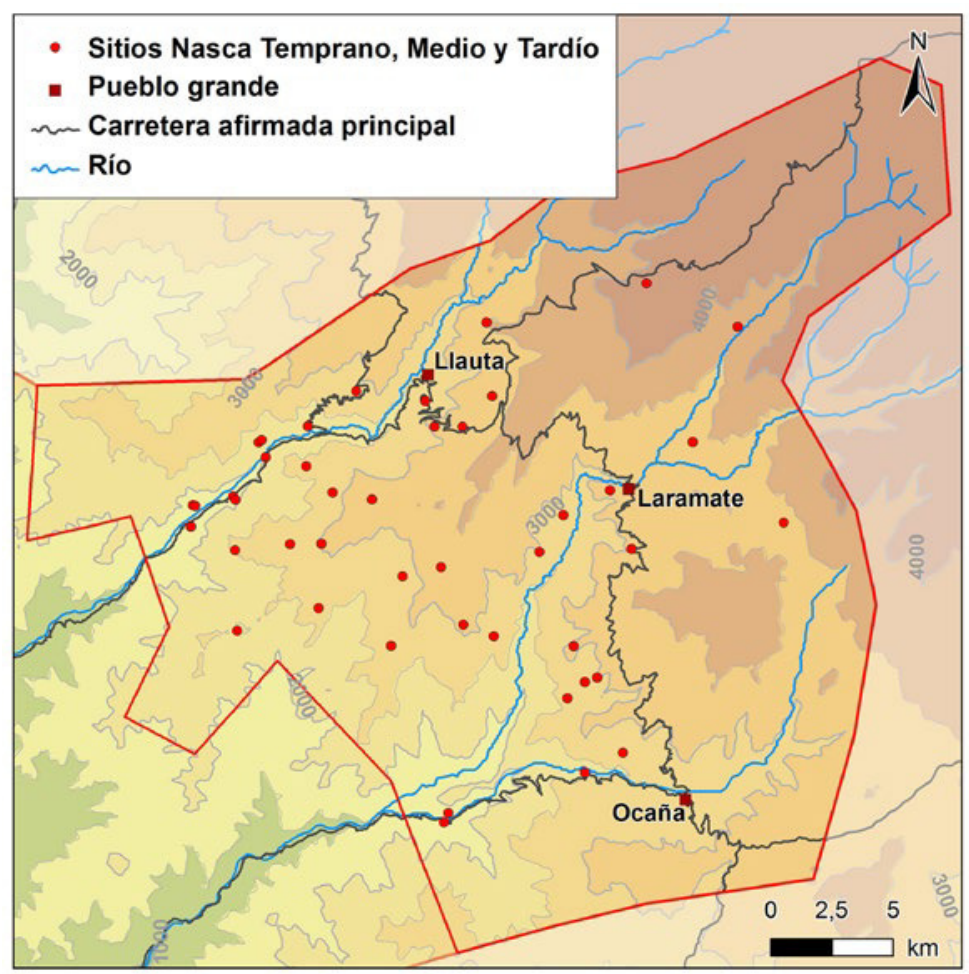

\section{Los sitios paracas y nasca en la sierra}

La ocupación Paracas en la sierra ha sido bien documentada desde el primer año de investigación en la zona, siendo luego largamente confirmada durante los trabajos de prospección realizados en los años sucesivos. Ahora sabemos que, del total de sitios registrados durante los trabajos de campo, 99 sitios resultaron ser de filiación Paracas — 28\% del total — (Fig. 6). De estos, 87 sitios pudieron ser clasificados en alguna de las fases estilísticas conocidas. De este modo, tenemos 5 sitios pertenecientes a la época Paracas Temprano, 30 a la época Paracas Medio y 52 a la época Paracas Tardío.

A partir de estas cifras, se puede postular que la ocupación Paracas en la sierra se fue consolidando con el paso del tiempo en base a una población autóctona. En este sentido, se observa un incremento importante de sitios en la época Paracas Tardío (fases Ocucaje 8 y 9), tiempo en el cual los sitios de vivienda tienden a ser más grandes y en el que además aparecen las primeras construcciones de carácter público, como los edificios en forma de flor registrados en Cutamalla y en otros sitios de la zona (Fig. 6). A este tiempo también se debe atribuir la construcción de la mayoría de terrazas agrícolas que se encuentran dispersas en diversos puntos de la zona, las cuales, desde entonces, se habrían utilizado continuamente, tal como ocurre hasta la actualidad'.

Por otro lado, las evidencias indican que la ocupación Nasca en la sierra presenta un declive con respecto a la época Paracas, aunque parece que esta nunca dejó de ser importante. Así, se sabe que, del total de sitios registrados, 67 son de filiación Nasca - 19\% del total- (Fig. 7) pero solo 56 pudieron ser clasificados según alguna de las fases estilísticas conocidas. En este sentido, se llegó a saber que solo tres sitios pertenecen a la época Nasca Temprano, 42 a la época Nasca Medio y solo 9 a la época Nasca Tardío.

Según estas cifras, resulta un poco extraño que solo tres sitios pertenezcan a la bien conocida época Nasca Temprano, mientras que la mayor cantidad de sitios daten de la época Nasca Medio. Una razón para esta relación desigual podría ser que durante la época Nasca Temprano el mayor 
foco de asentamiento estaba en los valles de la costa y yunga, donde se encontraba la mayor concentración de la población nasca. Al mismo tiempo es posible sugerir que en esa época en la sierra vivían mayormente agricultores y pastores, quiénes utilizaban cerámica doméstica o de tipo utilitario y en menor cantidad la cerámica fina. Esta situación habría cambiado en la época Nasca Medio, cuando las condiciones climáticas empeoraron considerablemente en la costa — los estudios del paleoclima indican que hubo un aumento de la aridez-y cada vez más grupos de pobladores se establecieron en la sierra. La disminución en el número de sitios en la época Nasca Tardío, al parecer, tiene que ver más con el aumento del tamańo de los asentamientos que con una disminución de la población, la cual sin embargo muestra un declive con respecto a la época anterior.

Siguiendo el esquema cronológico documentado en los valles de la costa, entre el desarrollo de los paracas y los nasca se reconoce una época de transición conocida como Proto Nasca o Nasca Inicial, la cual estilísticamente se relaciona con las fases Ocucaje 10 y Nasca 1, la cual tuvo una duración de aproximadamente 200 años (150 a.C.-50 d.C. $)^{6}$. Por ahora, esta época muestra en la sierra importantes diferencias con respecto a lo que sucedía en la costa. En este sentido, registramos una notable disminución en el número de sitios con respecto a la época precedente (Paracas) o a la sucesiva (Nasca), donde solo 9 sitios — menos del 3\% del total—, presentan una ocupación de este tiempo. Esta situación contrasta tremendamente con lo que ocurría durante ese mismo tiempo en la costa y la yunga, en donde se registró un notable incremento en el número de asentamientos y, por ende, en el número de habitantes (ver Isla y Reindel en este volumen).

Este hecho podría deberse a diversos factores, entre los que se debe tener en cuenta la ausencia de materiales diagnósticos en la superficie de los sitios o la superposición de ocupaciones de otras épocas. Asimismo, teniendo en cuenta los datos derivados del estudio del paleoclima, se sabe que en este tiempo hubo condiciones favorables de humedad en los valles de la costa, lo que habría provocado que el foco de asentamiento se haya concentrado en la parte baja de los valles. Las evidencias indican, además, que esto habría ocurrido en el contexto de una influencia externa promovida por la llegada de poblaciones Topará a los valles de Palpa y Nasca, lo cual eclipsó el desarrollo de la cultura Paracas tanto en la costa como en la sierra. No obstante, el descubrimiento de sitios de este tiempo debajo de ocupaciones posteriores, como en el sitio de Huayuncalla (ver más adelante), o en Cutamalla mismo, indica que la sierra no se quedó deshabitada, sino que mantuvo una ocupación estable, que al parecer no dejó de ser importante.

\section{Características de los sitios Paracas, Nasca y de la época de transición en la sierra}

La mayoría de los sitios paracas y nasca en la sierra están localizados entre 2200 y 3500 msnm, en lugares que presentan un alto potencial agrícola. Solo unos pocos sitios fueron localizados sobre los $3500 \mathrm{msnm}$, y por lo general comprenden unas pocas unidades de vivienda asociadas a numerosos corrales, algunos muy grandes. No es posible pensar que los paracas o los nasca no tenían rebaños de camélidos en las alturas o que estos no hayan tenido el mismo significado que en otras épocas. Por el contrario, las evidencias indican que en la época Paracas Tardío se dio un incremento en la crianza de camélidos y en la explotación de su lana. Por tanto, la poca cantidad de sitios de estas épocas en la puna podría deberse a que los pastores de altura utilizaban principalmente cerámica llana. También es posible que antiguamente, como ocurre hoy en día, los pastores de la sierra hayan subido a la puna solo de manera temporal para el cuidado y traslado de los rebańos, de tal modo que no dejaron muchos restos de su estancia en la zona. Esto explicaría la falta de un mayor número de sitios de habitación y la ausencia de materiales de vivienda en ellos.

Entre los 2200 y $3500 \mathrm{msnm}$, los asentamientos paracas y nasca se establecieron preferentemente sobre los cerros o colinas prominentes de la zona, desde donde se tenía una buena visibilidad del área circundante. En estos lugares las estructuras arquitectónicas fueron construidas sobre terrazas localizadas en la parte alta de los cerros y colinas, usualmente en las zonas que estaban más 
Figura 8. Foto satelital de Plazapampa, conjunto arqueológico compuesto por varios sitios de habitación nasca y del Intermedio Tardio que se ocupan la cima de los cerros. Se localiza justo al oeste del poblado de Laramate (foto Markus Reindel).

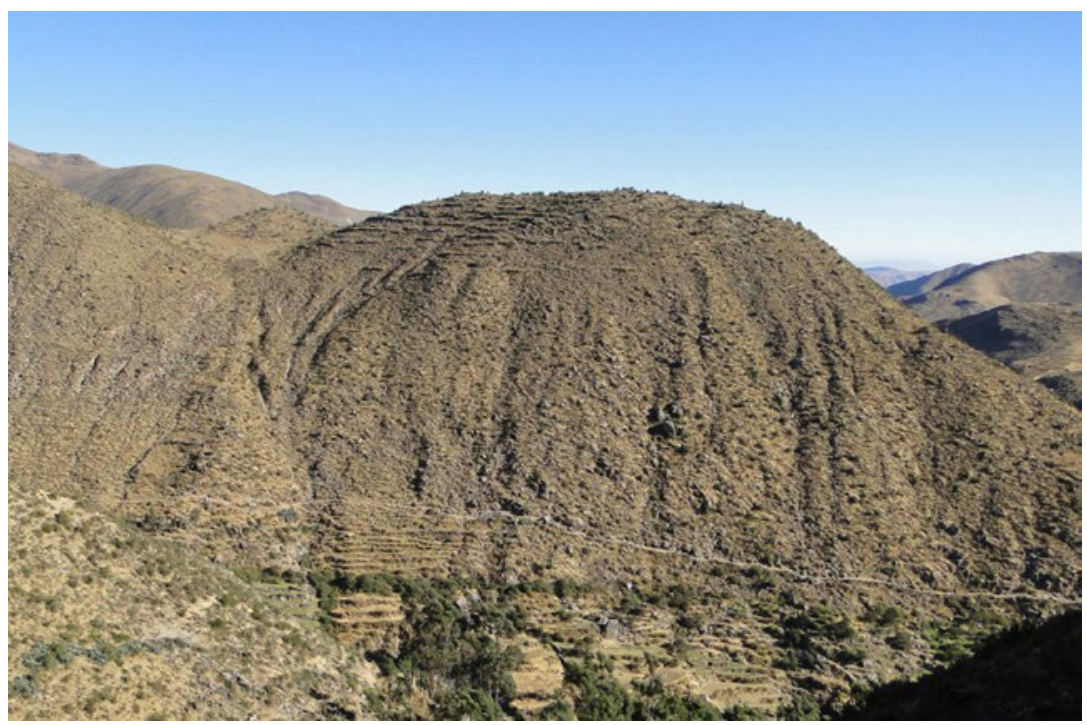

protegidas del viento (Fig. 8). En varios casos, los asentamientos de ambas épocas ocuparon los mismos espacios, llegando incluso a sobreponer o reutilizar construcciones antiguas. Esto ocurre, por ejemplo, en los sitios de Mallma y Suito Orqo, en donde las construcciones nasca se sobreponen a las Paracas o están ocupando áreas adyacentes.

La forma típica de las construcciones paracas y nasca es muy similar. En la mayoría de casos comprende recintos de planta circular u ovalada, cuyo diámetro o lado más largo varía entre tres y seis metros. Estos recintos fueron establecidos en filas sobre terrazas escalonadas que fueron adaptadas a la pendiente del terreno, mientras que en las partes más planas se disponen alrededor de espacios abiertos o patios, conformando grupos o unidades domésticas que posiblemente fueron habitados por familias o personas emparentadas (Fig. 9). Asimismo, con frecuencia se observa algunas terrazas divididas por paredes medianeras que también definen unidades domésticas. La presencia de manos de moler o batanes indica claramente la función doméstica de tales unidades. Por otro lado, en muy pocos casos - con excepción de los sitios en forma de flor, ver más adelante—, se han registrado recintos o estructuras arquitectónicas más grandes o de carácter público, que no sean patios o espacios de uso comunal.

En cuanto a la técnica constructiva, tanto los paracas como los nasca construyeron sus recintos con muros de doble cara, los cuales estaban hechos por una doble hilera de piedras y relleno interior. En muchos casos la primera hilada estaba compuesta por grandes piedras asentadas directamente en el terreno natural. Según la cantidad de piedras acumuladas en los escombros, se puede inferir con bastante certeza que las paredes tenían poca altura — no eran más altas que 1 metro-y, por tanto, es posible pensar que los recintos hayan tenido postes complementados con ramas o quincha para sostener techos ligeros hechos de materiales perecibles. En ningún caso se ha detectado restos de adobes para sugerir el uso de este material en los muros. Algunas veces, el interior de las casas o recintos fueron subdivididos con delgados muros y en otros se observan muros adosados en las paredes exteriores, con los que se formaron pequeños espacios que podrían haber funcionado como despensa para guardar objetos o productos alimenticios.

De acuerdo con las observaciones de superficie, aparentemente la mayoría de asentamientos presentan una sola fase constructiva y, por consiguiente, un solo momento de ocupación. No obstante, en varios sitios, especialmente en aquellos en donde se realizaron excavaciones de prueba, se registraron materiales de diferentes épocas en un mismo recinto, lo que indica claramente que algunos sitios fueron reutilizados algún tiempo después. 


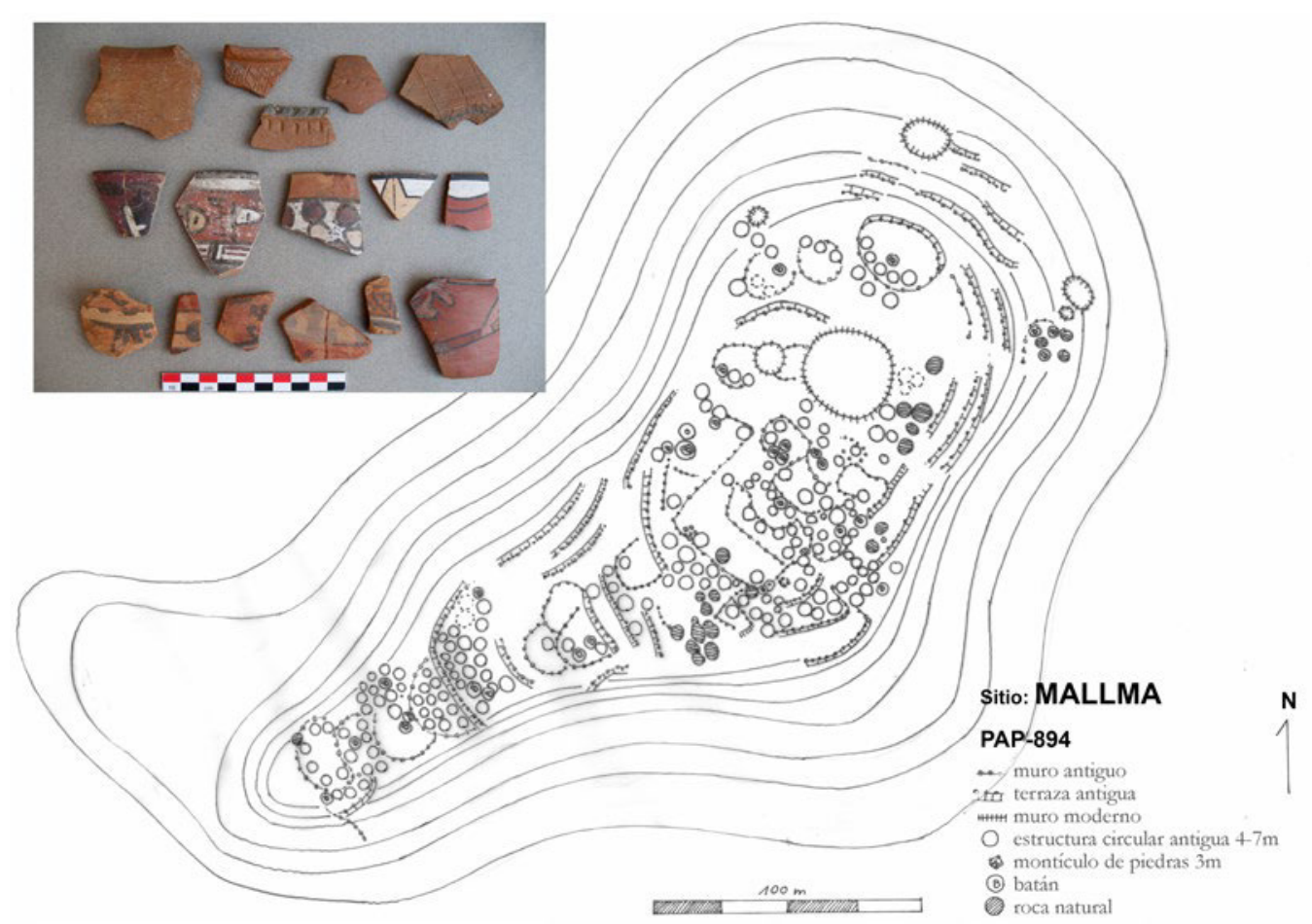

Figura 9. Croquis esquemático de Mallma (sitio PAP-894), donde se observan numerosos recintos de habitación de filiación Paracas y Nasca. Algunos recintos también fueron ocupados durante el Periodo Intermedio Tardio (dibujo Carolina Hohmann).

Para la época Paracas hemos registrado un grupo de sitios que por sus características constituyen un caso único en la región. En estos, además de un sector con recintos de uso doméstico y vivienda, se encuentra otro sector con un grupo de estructuras arquitectónicas más grandes y complejas, compuestas por un patio hundido rodeado — en un nivel superior y a cierta distancia - por una serie de recintos en forma de «D», cuyo lado recto está mirando hacia el patio hundido. Delante de cada uno de los recintos en «D» se encuentra una terraza delimitada por un alineamiento de piedras. Vistas desde arriba, estas estructuras se asemejan a la forma de una flor, nombre que adoptamos aquí para referirnos a ellas (Fig. 10). Hasta el momento se han identificado siete sitios con este tipo de estructuras arquitectónicas, la mayoría de los cuales se localizan en los cerros o colinas altas que bordean el río Laramate y solo dos en las márgenes altas del río Ocańa. Estos sitios además tienen la particularidad de que se pueden ver entre sí a largas distancias, lo que evidentemente les otorga una condición especial.

Desde el punto de vista constructivo, el patio hundido está delimitado por un muro conformado por una hilera de piedras planas y alargadas (tipo lajas), cuyos lados más planos miran hacia el interior, mientras que los recintos en «D» están construidos con una hilera de grandes piedras de campo dispuestas en posición de soga. Usualmente se trata de muros bajos que tienen entre una y dos hiladas de piedras. También en este caso es posible que los recintos hayan tenido postes y quincha para sostener techos sencillos.

Según los materiales asociados, todos estos sitios fueron establecidos en la época Paracas Tardío, en relación con la fase Ocucaje 9, tiempo en el cual se estima que la sociedad Paracas experimentó una reorganización de alcance regional. Este tipo de estructuras arquitectónicas es único en la zona y parece haber sido una creación exclusiva de los arquitectos paracas que vivían en la sierra. Si bien en el sector de viviendas también se observan recintos en forma de «D», estos no tienen 
patios hundidos y se disponen alrededor de espacios abiertos más grandes y en relación con otros recintos de formas más variadas. En este sentido, este modelo arquitectónico en forma de flor no se repitió como tal ni en otros lugares ni tampoco en otros tiempos. De acuerdo con su conformación y estructuración interna, se trataría de construcciones en donde se habrían realizado actividades productivas y también otras de carácter festivo o religioso.

Solo durante la época de transición entre Paracas y Nasca, se observa una suerte de continuidad de este tipo de construcciones en otros sitios de la zona, aunque con ciertas diferencias con respecto al modelo original. En tal sentido, durante las excavaciones en Huayuncalla, que se encuentra a poca distancia de Cutamalla, y en otros sitios localizados en el sector de Collanco, en la parte alta de la zona yunga del valle de Palpa, se han registrado estructuras arquitectónicas parecidas, pero en las que el patio central apenas es hundido y a la vez tiene una forma más ovalada e irregular. Asimismo, los recintos dispuestos alrededor del patio apenas conservan la forma de «D», también tienden a ser más ovalados y además fueron construidos excavando parcialmente el terreno natural. También se observa que la construcción de los recintos es más descuidada y en varios casos se han dejado espacios libres alrededor del patio. Otra diferencia es que tampoco existe un espacio intermedio entre el patio y los recintos dispuestos alrededor, sino que los mismos recintos están delimitando dicho patio.

En cuanto a su organización interna, en este caso no se nota una marcada diferencia entre las estructuras domésticas y aquellas de uso comunal o público. Si bien se pueden distinguir construcciones en las cuales se habrían realizado exclusivamente actividades productivas, al mismo tiempo hay otras en donde al parecer se realizaban simultáneamente actividades productivas y de vivienda. Todos estos rasgos marcan la diferencia entre las estructuras arquitectónicas en forma de flor de este tiempo, con respecto a las construcciones de la época precedente, aunque no se puede dejar de percibir entre ambas un cierto parecido en el modelo arquitectónico. Los cambios operados en el modelo constructivo también se pueden observar en la producción artesanal, v.g. en la cerámica, en cuya producción se nota claramente la influencia de la cultura Topará.

Por otro lado, al igual que en la época Paracas Tardío, este modelo arquitectónico parece ser exclusivo de la sierra y de la parte alta de la yunga, ya que no se encuentra en las secciones más bajas de los valles y tampoco en la zona de la costa. Tampoco se repite después, durante el desarrollo de la cultura Nasca, lo que nos indica que se trata de un modelo propio de la sierra, específicamente de la zona comprendida entre Laramate y Ocaña, estando vigente solo durante la época Paracas Tardío y con ligeros cambios continuó hasta la época de transición de Paracas a Nasca.

Finalmente, se debe indicar que, en contraste con otros períodos de tiempo, donde las tumbas o las estructuras funerarias pueden ser identificadas por rasgos arquitectónicos visibles en la superficie de los sitios, como las llamadas chullpas o kuntis del Horizonte Medio, en el caso de los paracas y los nasca, y también en la época de transición entre ambos, no ha sido posible identificar sus cementerios o lugares de enterramiento, tal como sí ocurre más abajo, en la yunga o en la costa. En este sentido, solo por referencias orales obtenidas de algunos pobladores de la zona, se estima que los cuerpos de los difuntos eran enterrados en pozos sencillos que fueron excavados en el terreno natural y cubiertos con lajas.

\section{Los trabajos de excavación}

En forma paralela a los trabajos de prospección, también realizamos excavaciones en área y excavaciones de prueba en varios sitios pertenecientes casi todos los períodos, especialmente en aquellos de filiación Paracas y Nasca. ${ }^{7}$ En tal sentido, a continuación vamos a hacer referencia a las excavaciones en área realizadas en los sitios de Cutamalla y Huayuncalla, en los cuales se ha puesto al descubierto importantes evidencias de ocupación relacionadas con las épocas Paracas y Nasca, así como también de la época de transición entre ambas (Reindel e Isla 2013, 2017). En Huayuncalla, además, se excavaron diversas estructuras arquitectónicas pertenecientes a un asentamiento Wari, el cual parece haber sido uno de los más importantes de la zona. 


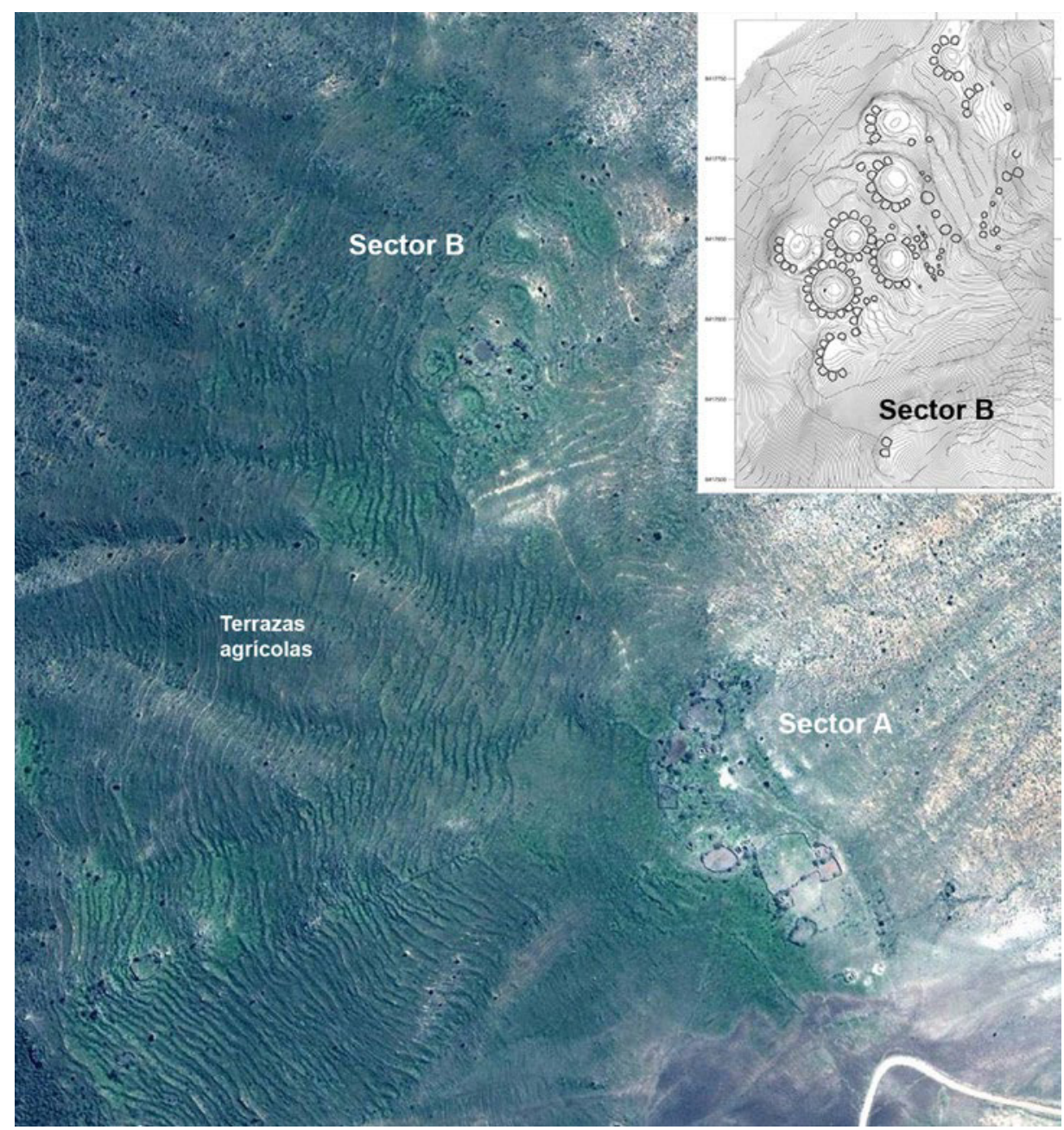

Figura 10. Foto satelital de Cutamalla (sitio PAP-767), en donde se observan los dos sectores del sitio y el gran conjunto de terrazas agricolas que circundan su lado oeste. Se adjunta un plano en detalle del sector $B$, donde destacan las estructuras arquitectónicas en forma de flor (foto Quickbird 2005).

\section{Las excavaciones en Cutamalla}

El sitio de Cutamalla se encuentra a la altura del kilómetro 12 del camino que va de Laramate hacia Ocaña, en la margen izquierda del río Laramate, ocupando la parte alta y media de una loma alargada que se proyecta casi de sur a norte desde los cerros más altos. El sitio se localiza a 3,200 msnm, entre las coordenadas UTM 515,750 a 516,000 E y 8'417,200 a 8’417,800 N.

El sitio fue dividido en dos sectores a partir de las evidencias de superficie, uno de carácter más habitacional (sector A) que ocupa la parte más alta y otro de carácter público y ceremonial (sector B) que ocupa la parte baja (Fig. 10). Entre ambos sectores, de manera especial en todo el lado oeste del sitio, se encuentra un gran complejo de terrazas agrícolas que han sido adaptadas a la topografía inclinada del terreno. En la actualidad dichas terrazas se encuentran bastante erosionadas y en completo abandono.

Las construcciones en el sector A comprenden los cimientos y muros de una serie de recintos de piedra, de planta ovalada, circular y en forma de «D», los cuales se disponen en forma aislada o 
en grupos, separados por patios y grandes espacios abiertos adaptados a la topografía del terreno. Se observa varios conjuntos de este tipo de estructuras que posiblemente corresponden a unidades domésticas. Se debe indicar que la mayoría de las estructuras arquitectónicas en este sector han sido afectadas por la construcción de corrales actuales, en los cuales se han reutilizado muchas de las piedras que conformaban los muros antiguos. Por otro lado, en el sector B se encuentra un grupo de diez construcciones bastante grandes que en términos generales presentan una planta en forma de una flor. Cada conjunto comprende entre 5 a 15 recintos en forma de «D» que miden unos 5 metros por 6 metros de lado, los cuales están dispuestos alrededor de un patio hundido que tiene unos 20 metros de diámetro. Delante de cada uno de los recintos en forma de «D", mirando hacia el patio hundido, se encuentra una terraza de más o menos 1,3 metros de ancho, que estaba delimitada por un delgado alineamiento de piedras. Solo tres de estos conjuntos están completos, mientras que los otras solo presentan parte del patio y algunos recintos en «D». Aparentemente esto obedece a su adaptación al terreno inclinado

Las evidencias documentadas en Cutamalla, tanto en el sector A como en el B, indican que el sitio fue construido en la época Paracas Tardío, en relación con la fase Ocucaje 9, y después reutilizado en la época de transición de Paracas a Nasca, en relación con las fases Ocucaje 10 y Nasca 1, las cuales se relacionan con la influencia Topará (Tabla 1). Las excavaciones en el sector A se concentraron en varias unidades arquitectónicas en forma de «D» con patio delantero, mientras que en el sector B se concentraron en uno de los edificios más completos en forma de flor (Fig. 11).

En base a los rasgos arquitectónicos: materiales de construcción, técnica constructiva, forma y organización de los recintos, se puede decir que todas las estructuras están conformadas según un mismo diseño, y fueron construidas en solo momento. Así, el primer paso fue definir un espacio central o patio hundido, alrededor del cual se establecieron una serie de recintos en forma de "D", todos casi del mismo tamaño, con lo cual se conformó una estructura arquitectónica en forma de flor. Después de esto, el siguiente paso en el proceso constructivo fue el establecimiento de un recinto hundido al interior de cada recinto en "D", ninguno de los cuales es igual al otro en todos sus detalles. No obstante, en todos los casos se puede ver la repetición constante del modelo original. Estos recintos hundidos algunas veces estaban revestidos con piedras y al parecer algunos habrían cumplido la función de depósitos.

En todos los casos, los materiales encontrados comprenden una gran cantidad de fragmentos de cerámica, en donde destaca la presencia artefactos para la producción alfarera y también una buena cantidad de husos y piruros, puntas y lascas de obsidiana, así como algunos artefactos de molienda.

Teniendo en cuenta los rasgos arquitectónicos y los materiales asociados, se puede decir que en las construcciones en forma de flor del sector $\mathrm{B}$ se realizaron actividades públicas y comunales relacionadas con la producción de bienes y posibles actividades festivas. Aunque los datos no son del todo concluyentes, es evidente que el patio hundido - por su ubicación y rodeado de los recintos en «D»— tuvo una función especial, siendo el espacio donde se habrían realizado rituales festivos y religiosos. Los silos y pozos de quema documentados en el patio hundido estarían en relación con estas actividades. Por otro lado, los numerosos artefactos recuperados en los recintos en «D»y al interior de los recintos hundidos, indican claramente que en estos se desarrollaban actividades productivas como son: la elaboración de cerámica, la fabricación de puntas de obsidiana y el hilado de lana. Tampoco se descarta el uso de algunos de los recintos hundidos como silos o depósitos, en donde se guardaban los productos de la zona — agrícolas y ganaderos- que luego se habrían trasladado en caravanas de llamas a la costa (Mader et al. 2018).

Desde esta perspectiva, Cutamalla habría sido uno de los principales centros de producción y acopio de bienes que luego se trasladaban a la costa, en donde se encontraban los centros poblados más importantes de la cultura Paracas. Esta situación claramente se habría replicado en la época de transición de Paracas a Nasca, tiempo en el cual se observa la reutilización de la mayoría de recintos en Cutamalla. Al respecto es importante recordar que justo en este tiempo, en la costa ocurrió un 
Tabla 8. Lista de fechados de C14 para contextos registrados en Cutamalla, Huayuncalla y Collanco, los cuales muestran consistentemente el promedio de edad estimado para la ocupación de esos sitios entre la época Paracas Tardio y la época de transición de Paracas a Nasca (fechados adicionales se pueden ver en Mader et al. 2018: 260).

\begin{tabular}{|c|c|c|c|c|c|c|}
\hline $\begin{array}{l}\text { Número de } \\
\text { muestra }\end{array}$ & Sitio & $\begin{array}{l}\mathrm{N}^{\circ} \text { Contexto } \\
\text { Arqueológico }\end{array}$ & Edad C14 & \pm & Cal 1-sigma & Cal 2-sigma \\
\hline 1800 & Cutamalla & 24513 & 2157 & 23 & BC 348-170 & BC 355-112 \\
\hline 1801 & Cutamalla & 24514 & 2237 & 23 & BC $376-215$ & BC 386-207 \\
\hline 1806 & Cutamalla & 24515 & 2168 & 23 & BC 349-176 & BC $357-120$ \\
\hline 1808 & Cutamalla & 24492 & 2150 & 22 & BC 346-166 & BC 342-108 \\
\hline 1809 & Cutamalla & 24516 & 2168 & 23 & BC 349-177 & BC $357-120$ \\
\hline 1814 & Huayuncalla & 24493 & 2025 & 22 & $\mathrm{BC} 48-\mathrm{AD} 3$ & $\mathrm{BC} 92-\mathrm{AD} 49$ \\
\hline 1844 & Huayuncalla & 24517 & 2246 & 23 & BC 381-234 & BC 389-209 \\
\hline 1849 & Huayuncalla & 24518 & 2215 & 23 & BC 359-209 & BC 374-204 \\
\hline 1852 & Cutamalla & 24495 & 2133 & 16 & BC 199-118 & BC 342-99 \\
\hline 1853 & Cutamalla & 24519 & 2114 & 21 & BC 179-104 & BC 198-55 \\
\hline 1854 & Cutamalla & 24520 & 2149 & 22 & BC 346-166 & BC $352-108$ \\
\hline 1856 & Cutamalla & 24496 & 2210 & 17 & BC 357-208 & BC 363-204 \\
\hline 1862 & Cutamalla & 24507 & 2153 & 21 & BC 346-169 & BC 353-112 \\
\hline 1866 & Cutamalla & 24521 & 2205 & 22 & BC 357-206 & BC $363-202$ \\
\hline 1873 & Cutamalla & 24497 & 2248 & 17 & BC 382-235 & BC 388-211 \\
\hline 1878 & Cutamalla & 24508 & 2288 & 21 & BC 395-370 & BC $400-235$ \\
\hline 1881 & Cutamalla & 24498 & 2048 & 16 & BC 91-3 & $\mathrm{BC} 155-\mathrm{AD} 1$ \\
\hline 1884 & Cutamalla & 24509 & 2177 & 23 & BC 351-194 & BC 358-171 \\
\hline 1885 & Cutamalla & 24499 & 2087 & 17 & BC $158-56$ & BC $167-51$ \\
\hline 1886 & Collanco & 24500 & 2131 & 16 & BC 198-118 & BC 341-96 \\
\hline 1888 & Collanco & 24523 & 1939 & 21 & AD 27-82 & AD 9-124 \\
\hline 1891 & Collanco & 24510 & 2126 & 22 & BC 197-112 & BC $342-57$ \\
\hline 1892 & Collanco & 24511 & 2106 & 23 & BC 172-94 & BC 192-54 \\
\hline
\end{tabular}

notable incremento de la producción textil con la confección de finos mantos elaborados en base a fibras de camélidos, en relación con la fase Paracas Necrópolis. De este modo, se puede ver una directa conexión entre los asentamientos Paracas Tardío de la sierra, con aquellos de la costa, lo que se hizo más evidente en la época de transición, en relación con la cultura Topará.

\section{Las excavaciones en Huayuncalla}

El sitio de Huayuncalla fue establecido sobre una loma alargada que se localiza en la margen izquierda del río Laramate, a 1.5 kilómetros al oeste del caserío de Ispana, a la altura del kilómetro 15 del camino que comunica a los poblados de Laramate y Ocańa. Dicha loma se proyecta casi de noreste a sudoeste, bajando desde los cerros más altos en dirección al río Laramate, con laderas muy pronunciadas por los lados norte y sur. Huayuncalla se encuentra a 3,100 msnm y sus coordenadas UTM son 514,660 E y 8’414,280 N. 


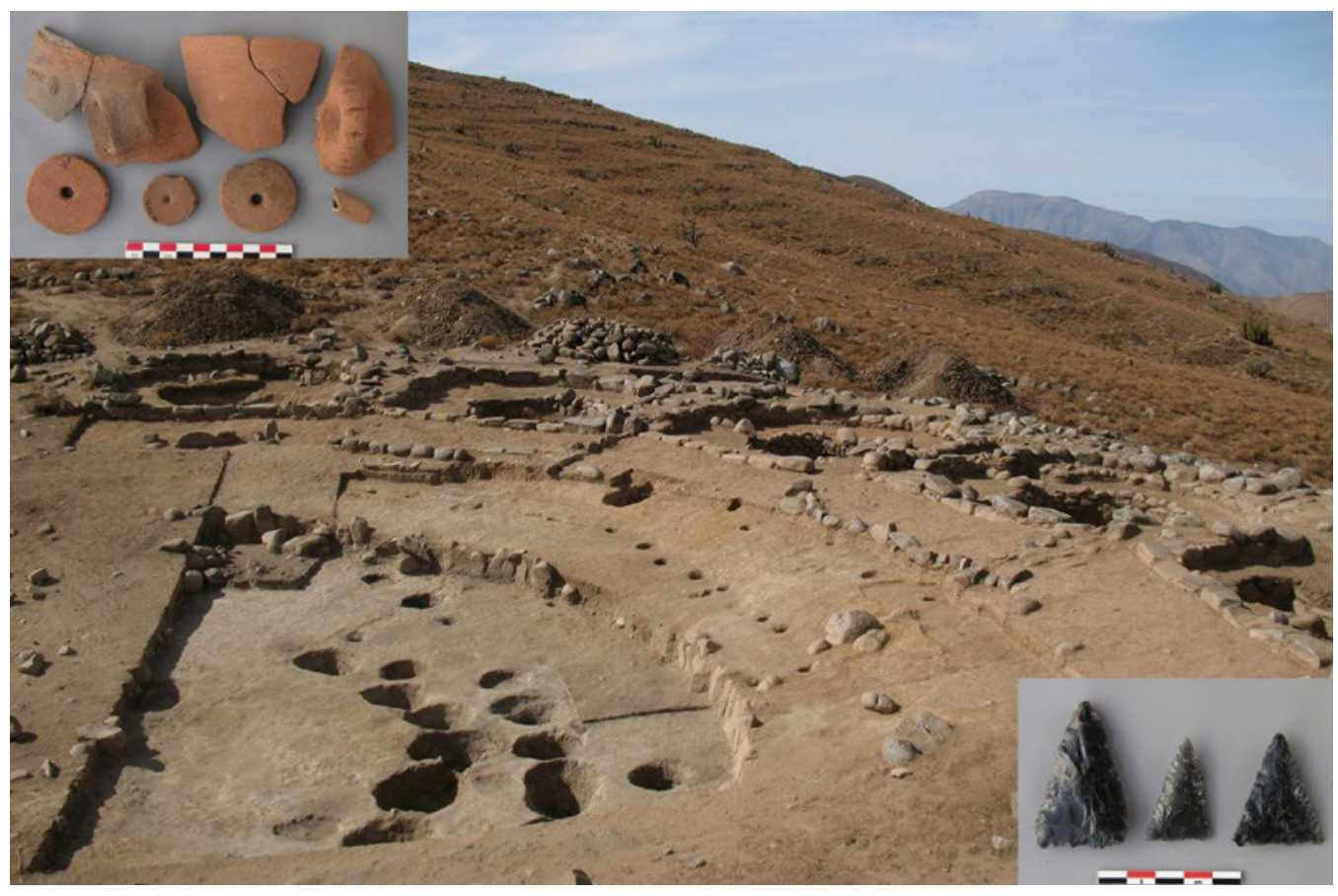

Figura 11. Vista de la excavación de uno de los edificios en forma de flor en Cutamalla, donde se observa el patio hundido, la terraza y los recintos en "D" a su alrededor. Nótese los silos, hoyos de postes y algunos de los materiales asociados (foto Johny Isla).

En el sitio se encuentran numerosas construcciones de piedra entre las que se puede distinguir espacios de planta ovalada y circular, así como grandes recintos y patios hechos con muros rectos que definen un patrón marcadamente ortogonal (Fig. 12). Gran parte de estas construcciones han sido destruidas en tiempos recientes para la construcción de grandes corrales, por lo que la mayoría de los muros se encuentran casi al nivel de la superficie del terreno, usualmente cubiertos por la vegetación arbustiva.

La concentración más grande de estructuras se encuentra en la parte alta del sitio, en donde destacan, por un lado, un numeroso grupo de recintos de planta ovalada y circular que varían entre 3 y 6 metros de diámetro, y por otro, una serie de muros rectos que conforman recintos de planta rectangular, los cuales están alternados con patios o espacios abiertos libres de construcciones. Entre estos, en el punto más alto, destacan dos recintos de planta circular dispuestos al interior de un recinto rectangular. Los cimientos de otros recintos más grandes de planta rectangular se observan en los grandes corrales al lado este del punto más alto. Asimismo, en toda la periferia norte del sitio se encuentran algunas estructuras funerarias bastante grandes, conocidas como kuntis, la mayoría de las cuales estaban saqueadas. Una de ellas, la más grande, es de forma rectangular y tiene tres compartimientos interiores. Esta estructura funeraria está construida con muros de piedra bastante sólidos y en su parte superior incluye grandes bloques de piedras que forman techos de tipo falsa bóveda.

Los materiales encontrados en la superficie del sitio indicaban la existencia de tres momentos de ocupación: la primera relacionada con la época de transición de Paracas a Nasca, la segunda a Nasca y la tercera a Wari. Excavaciones de prueba realizadas el 2008 en dos sectores distintos del sitio, permitieron reconocer que las construcciones de planta rectangular eran de filiación Wari, mientras que las de planta circular y ovalada, además de restos de filiación Wari también contenían materiales mezclados de épocas Paracas tardío y Nasca. En base a estas evidencias, el 2010 se realizaron excavaciones en área con la finalidad de obtener evidencias estratigráficas de los materiales registrados en la superficie y en las excavaciones de prueba. 
Las excavaciones en la Unidad 1 pusieron al descubierto varios recintos construidos en dos fases, relacionadas con la época 2 del Horizonte Medio (Fig. 12). Las excavaciones en la unidad 2, localizada en los dos recintos circulares delimitados por muros rectos en la parte más alta del sitio, permitieron descubrir que ambos recintos correspondían a estructuras funerarias de filiación Wari. Las construcciones Wari en esta parte del sitio se sobreponían a una ocupación Nasca — de las fases 5 y 7 - de la cual, al menos en el área excavada, no se han identificado restos de construcciones. Por otro lado, las excavaciones en la unidad 3 han puesto en evidencia varias viviendas de planta ovalada y circular, las cuales son más frecuentes en todo el lado sur y sudeste del sitio. De acuerdo con los materiales encontrados, algunos de estos recintos habrían sido construidos durante la época de transición de Paracas a Nasca — fases Ocucaje 10/Nasca 1-y luego reutilizados durante las ocupaciones Nasca y Wari. Finalmente, las excavaciones en la unidad 4 comprendieron una estructura funeraria intacta que contenía varios entierros de filiación Wari.

De este modo, las excavaciones en Huayuncalla nos han permitido confirmar que las estructuras arquitectónicas de planta rectangular fueron construidas durante el Horizonte Medio, en relación con la ocupación Wari en la zona. Lo mismo se puede decir de la mayoría de recintos de planta circular u ovalada visibles en la superficie del sitio, algunos de los cuales parece que fueron construidos en la época Paracas Tardío y luego reutilizados durante las ocupaciones Nasca y Wari.

Por otro lado, las excavaciones en la Unidad 1 también nos permitieron descubrir, debajo de las construcciones Wari, al menos tres recintos casi en forma de «D» muy parecidos a los de Cutamalla pero a la vez menos elaborados que aquellos (Fig. 13). Se trata de estructuras semi-subterráneas, que miden en promedio 5 por 6 metros de lado y están dispuestos uno al lado del otro. Estos recintos fueron construidos excavando la capa natural, con muros conformados por una hilera de grandes piedras canteadas dispuestas entre dos y tres hiladas. Los muros miden entre 40 y 50 centímetros de ancho y llegan hasta 60 o 70 centímetros de altura. Al interior de estos recintos se encuentra un espacio hundido de contorno circular de 3.5 a 3.8 metros de diámetro y 50 centímetros de profundidad, el cual también estaba delimitado con una hilera de piedras alargadas, tipo lajas, las cuales fueron colocadas en posición vertical y complementadas con pequeñas piedras. Alrededor de este espacio hundido se encuentra una especie de banqueta de 1.2 a 1.5 metros de ancho, la cual se hizo trabajando la capa natural y sobre la cual se formó un apisonado. Al no haber identificado ningún acceso, la banqueta conforma un nivel intermedio para entrar al recinto y salir del mismo.

En todos los casos estas construcciones tenían uno o dos niveles de uso, en relación a los cuales se han encontrado fragmentos de cerámica fina y utilitaria que muestran rasgos relacionados con el estilo Topará (Fig. 14). En algunos casos, tanto en las banquetas como en el fondo de los espacios hundidos, también se han identificado pequeños pozos excavados en el terreno natural, al interior de los cuales se han encontrado entierros de infantes y neonatos de esta época, los cuales se habrían depositado antes del abandono de las estructuras ${ }^{8}$.

Estas estructuras tienen un gran parecido con los recintos Paracas excavados en Cutamalla, aunque al mismo tiempo presentan diferencias importantes. Tal vez la más resaltante es la irregularidad de los recintos, en los cuales muchas veces apenas se distingue el lado recto de la forma de "D", de tal manera que frecuentemente adoptan una forma más ovalada. Así mismo, sus muros son más altos, pero menos elaborados y los espacios hundidos al interior son menos profundos. Es posible que estas diferencias se deban a que ambos tipos de construcción datan de épocas distintas pero sucesivas. No olvidemos que las estructuras de Cutamalla son de la época Paracas Tardío y las de Huayuncalla de la época de transición de Paracas a Nasca. En todo caso, las estructuras son más parecidas a las que se encuentran en los sitios de la zona de Collanco, con las cuales son contemporáneas.

Finalmente, es importante señalar que recientes prospecciones geomagnéticas realizadas cerca de la Unidad 1 de Huayuncalla y en el sitio PAP-815, ubicado inmediatamente al oeste, han revelado la existencia de otros grupos de recintos dispuestos alrededor de un espacio libre o posible patio hundido. Al parecer se trata de construcciones que repiten el mismo modelo arquitectónico de las estructuras en flor descubiertas en el sitio de Cutamalla, lo cual estaría indicando que Huayuncalla 
también tuvo una posición importante en la zona al final de la época Paracas, pero especialmente en la época de transición Paracas-Nasca.

\section{Comentarios finales y conclusiones}

Teniendo en cuenta que las investigaciones arqueológicas en la zona de las cabezadas, como usualmente se conoce a la sierra de Lucanas ubicada en la vertiente occidental de los Andes, eran prácticamente ausentes hasta antes del inicio de los trabajos del Proyecto Palpa-Lucanas, los resultados obtenidos en las varias temporadas de campo realizadas en la zona, desde el 2006 al presente, han sido tremendamente sorprendentes y a la vez gratificantes en varios aspectos. Primero, por la gran cantidad de sitios arqueológicos presentes en una zona que, al menos en la actualidad, parece bastante seca, agreste y poco poblada (Reindel 2010, 2012; Reindel e Isla 2013). Segundo, porque dichos sitios representan ocupaciones culturales que abarcan casi toda la historia prehispánica de la región, la cual, a su vez, muestra fuertes vínculos con el desarrollo cultural registrado en la costa (Reindel 2009; Isla 2010; Isla y Reindel 2017). Y, finalmente, porque el análisis combinado de los datos relacionados con el patrón de asentamiento y el paleoclima, tanto de la costa como de la sierra, muestra los mismos cambios a lo largo del tiempo, lo que indica que ambas zonas estuvieron integradas por un mismo proceso cultural que se mantuvo activo y dinámico a través del tiempo, tal como ocurre en la actualidad.

Asimismo, en las investigaciones en la sierra también nos llamó la atención la gran cantidad de terrazas agrícolas que se encuentran cerca o alrededor de muchos de los asentamientos prehispánicos, en especial en aquellos de filiación Paracas y Nasca. En este sentido, existen zonas donde las laderas y faldas de los cerros están completamente cubiertas por grandes complejos de andenes que, vistos en conjunto, forman parte de un extenso paisaje cultural. Hoy en día, debido a la escasez de agua y la baja densidad poblacional de la zona, solo una mínima parte de esas antiguas terrazas de cultivo siguen en uso, mientras que el resto se encuentra en total abandono. Lo mismo se puede decir de los grandes corrales ubicados arriba de los $3500 \mathrm{msnm}$, los cuales son testimonio de la importancia que tenía en la antigüedad el manejo y la crianza de camélidos.

En este contexto y, como ya se dijo antes, los trabajos en la sierra nos han permitido registrar y documentar un gran número de sitios pertenecientes a casi todas las épocas y períodos de tiempo, los cuales van al menos desde el final del período Formativo hasta la ocupación Inka en la región. Si bien la evidencia de ocupación más antigua en la sierra se ha registrado en el abrigo de Llamocca, donde hubo un campamento de cazadores-recolectores de 8000 años a.C. (Reindel e Isla 2013), los datos más concretos de ocupación en la zona datan de la época Paracas Medio (550-370 a.C.), a partir de la cual se nota un paulatino incremento de sitios que alcanzó uno de sus mayores picos durante la época Paracas Tardío (370-200 a.C.).

Justamente, esta es la primera vez que se tiene evidencias concretas de ocupación Paracas en la sierra, la cual fue largamente supuesta en los estudios arqueológicos de la costa sur, pero no documentada mediante un registro sistemático de sitios arqueológicos. Lo mismo se puede decir de los nasca, cuyos asentamientos se encuentran también en toda la vertiente occidental de los Andes, desde el litoral hasta la puna. De este modo, ahora sabemos que Paracas y Nasca no eran formaciones sociales solamente costeńas, como tradicionalmente se piensa, sino sociedades cuyo territorio y principal espacio de desarrollo comprendió tanto la costa, como la yunga y la sierra.

Con respecto a la época de transición entre Paracas y Nasca, tema central de este artículo, las evidencias indican que en este tiempo la sierra tuvo un notable declive en el número de asentamientos con respecto a la época Paracas Tardío. Así, mientras el patrón de asentamiento mostraba un alto número de sitios (52) durante la época Paracas Tardío, en la época de transición este número disminuyó sensiblemente a solo 9, lo cual se hizo aún más evidente durante la época Nasca Temprano (3). Esta situación, evidentemente, plantea varias preguntas sobre lo que ocurrió con la gente en la sierra. ¿Qué pasó entonces?, ¿̇a dónde se fue la gente?, ¿̇e quedó despoblada la sierra?, etc. 


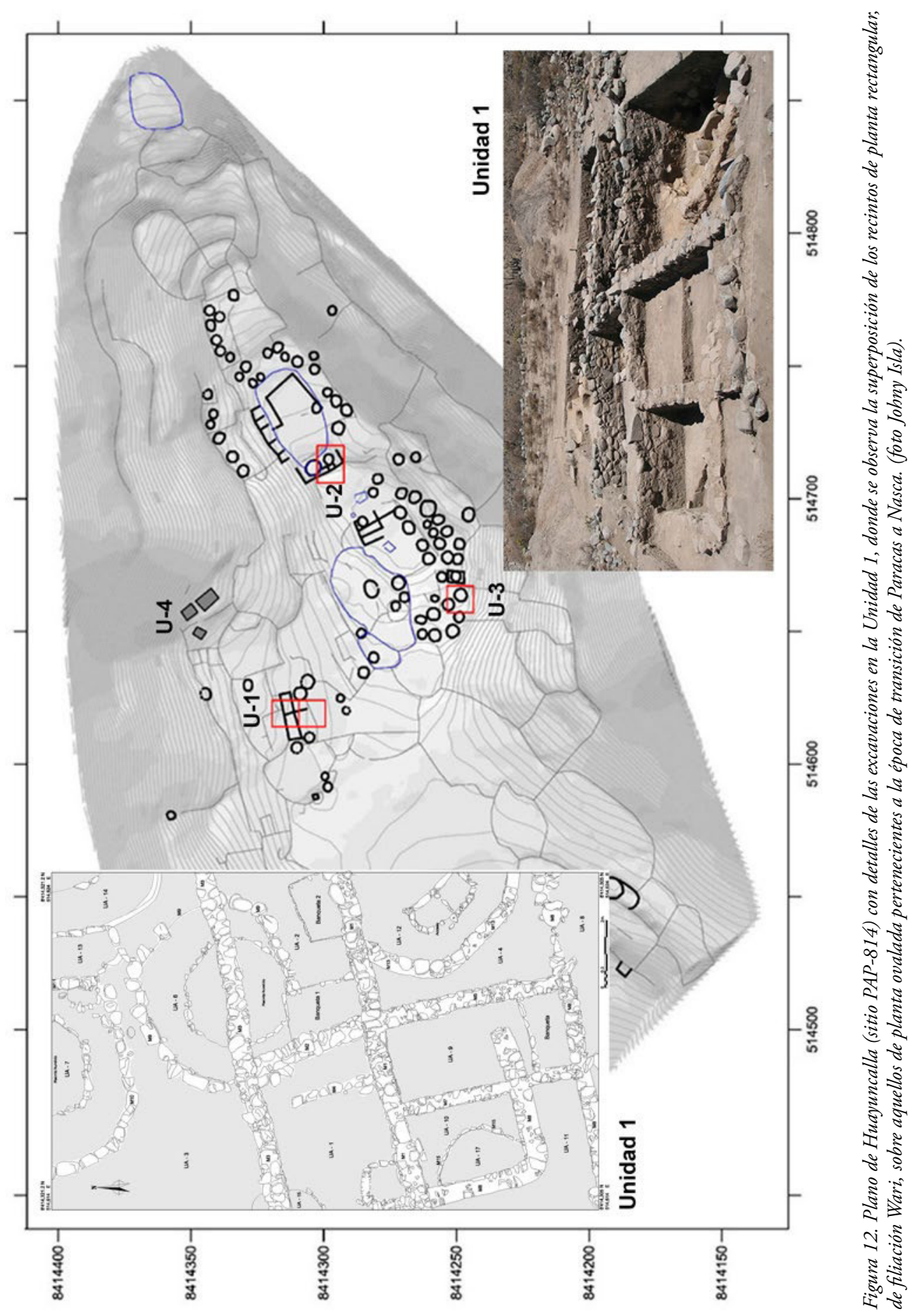




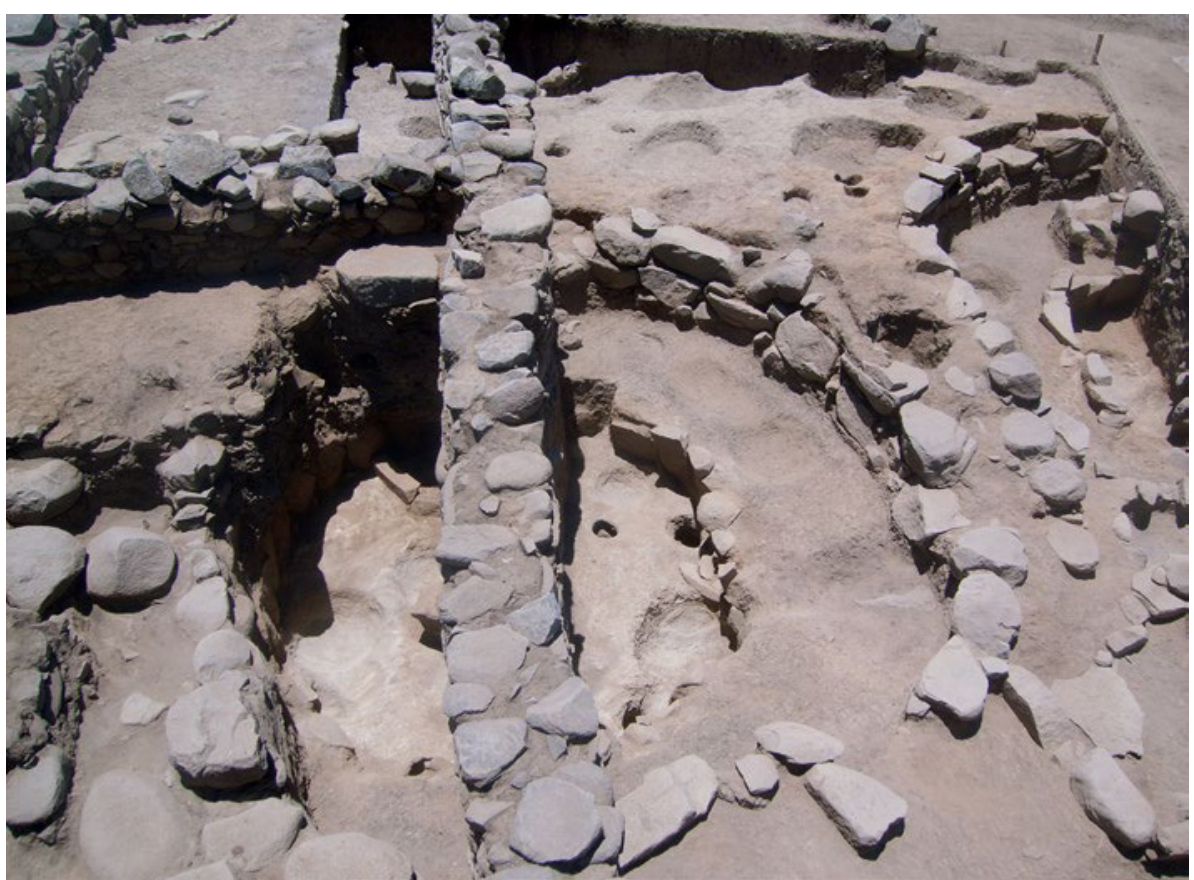

Figura 13. Primer plano de uno de los recintos de planta ovalada, donde se observa el espacio hundido al interior y la banqueta alrededor. Nótese el muro recto que se sobrepone a dicho recinto (foto Johny Isla).
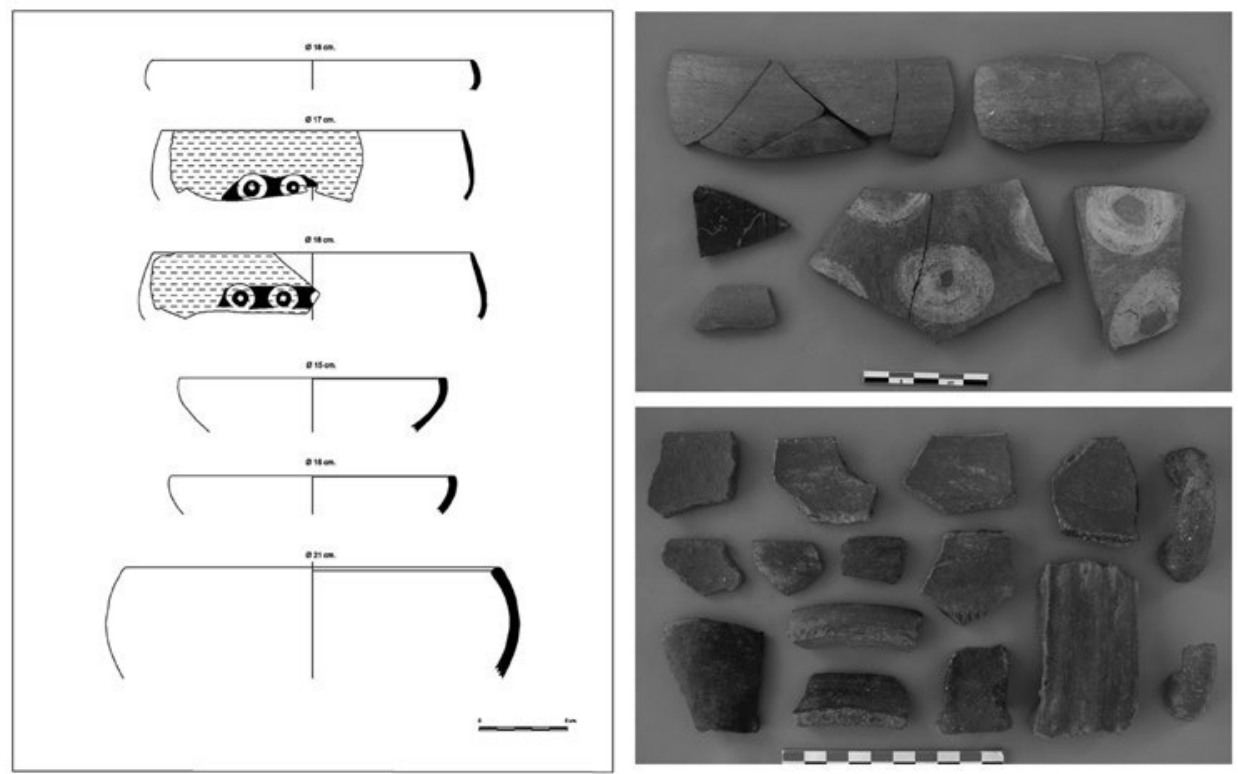

Figura 14. Dibujos y fotos de fragmentos de cerámica encontrados en los recintos ovalados de Huayuncalla, los cuales muestran rasgos típicos de la época de transición de Paracas a Nasca (gráfico elaborado por los autores). 
Las respuestas a esas preguntas las podemos encontrar en los resultados obtenidos, por nosotros mismos, durante los estudios de patrones de asentamiento en la costa (y parte de la yunga) y en aquellos realizados sobre el paleoclima en la región. Dichos resultados indican que, en ese tiempo, en la época de transición, el foco de asentamiento estuvo en los valles de la costa, en los cuales se registró una alta concentración poblacional y uno de los picos más altos en el número de asentamientos de todos los tiempos (Reindel 2009; Isla 2010). Esta situación habría sido provocada por la llegada masiva de grupos de pobladores de la sierra, así como también del valle de Ica y de otros de más al norte y, a la vez, favorecida porque en esa época, según los estudios del paleoclima, todavía se mantenían las condiciones favorables de humedad vigentes durante todo el período Formativo en la región (Eitel et al. 2005; Eitel y Mächtle 2009; Mächtle y Eitel 2013). Desde nuestra perspectiva, este evento habría sido promovido por gente de la cultura Topará, la cual en ese tiempo estaba extendiendo su área de influencia hacia los valles de Ica y también hacia la cuenca del río Grande (Menzel 1971; Massey 1986; Wallace 1986; Peters 1997; ver también Isla y Reindel en este volumen).

Entonces, volviendo a la sierra, por el momento se puede decir que, en la época de transición de Paracas a Nasca, gran parte de la población migró hacia los valles de la costa, aunque al parecer la sierra no se quedó del todo vacía. En este sentido, debemos resaltar que, si bien las evidencias de superficie indican que durante este tiempo hubo una importante disminución en el número de sitios y por consiguiente en el número de habitantes, las recientes excavaciones realizadas en sitios de la yunga (en Collanco) y la sierra (en Cutamalla y Huayuncalla) vienen aportando nuevos datos que pueden cambiar esta percepción?.

En este sentido, las excavaciones en Cutamalla han puesto en evidencia que tanto los edificios en forma de flor como los recintos en "D», fueron construidos y ocupados al final de la época Paracas Tardío, en relación con la fase Ocucaje 9. Sin embargo, las mismas excavaciones han permitido exponer evidencias que indican claramente que algunas de estas construcciones se reutilizaron o siguieron en uso también durante la época de transición de Paracas a Nasca. Esto último se ha documentado especialmente en el sector A del sitio, en donde se excavaron unidades arquitectónicas bastante grandes, donde se encontraron muchos materiales, especialmente cerámica, pertenecientes a esta época. Esto indica que la ocupación de este tiempo ocurrió incluso con mayor intensidad que antes y que la sierra siguió teniendo un rol importante en la economía de una sociedad cuyos centros principales estaban en la costa. Lo mismo se puede decir en el caso de Huayuncalla, en donde, debajo de las construcciones del Horizonte Medio, las excavaciones han puesto al descubierto varios recintos de planta ovalada o casi en forma de «D" pertenecientes a un asentamiento de la época de transición de Paracas a Nasca. En ambos sitios, lo interesante es que la cerámica asociada a dichas construcciones muestra rasgos muy parecidos al estilo Topará.

A la luz de estas evidencias, se puede decir con bastante certeza que la influencia de la cultura Topará, como lo sugirieron Menzel (1971), Wallace (1986) y Massey (1986), también alcanzó la parte alta de los valles de Palpa, con lo que su área de desarrollo comprende el mismo territorio antes ocupado por los paracas y luego por los nasca. Esto prueba, una vez más, que la vertiente occidental de los Andes — entre la costa y la sierra — estuvo integrada por los mismos procesos culturales a lo largo del tiempo ${ }^{10}$.

A partir de esto, es posible plantear que durante la época de transición de Paracas a Nasca, como al parecer también ocurrió antes y después, los habitantes de la sierra, y en especial los ocupantes de Cutamalla, estuvieron dedicados a la producción de bienes de consumo de la zona, v.g. productos agrícolas de altura, así como al acopio y la transformación de otros recursos como la obsidiana - para la fabricación de cuchillos y puntas de proyectil_ y muy especialmente la lana de camélidos — destinada a la producción de tejidos—. Dichos bienes habrían sido luego transportados a la costa, en donde se encontraban los asentamientos y poblados más importantes de la época, en donde residía una élite de personas que hacía uso y usufructo de dichos bienes. Cabe recordar que 
justo en esta época, en la costa hubo una gran demanda de fibras de camélidos para la producción de textiles, los cuales, como todos sabemos, alcanzaron su máximo esplendor en la fase Necrópolis.

Desde esta perspectiva, ahora se puede entender mejor los fuertes lazos de integración costasierra que hubo a lo largo del tiempo en los valles de Palpa, los cuales al parecer alcanzaron su mayor intensidad durante la época de transición de Paracas a Nasca. Seguramente futuras investigaciones en el área de estudio nos ayudarán a mejorar los conceptos y planteamientos expuestos aquí.

\section{Agradecimientos}

Los resultados presentados en este artículo se derivan de las investigaciones interdisciplinarias realizadas en el marco del Proyecto Arqueológico Palpa-Lucanas, los cuales fueron financiados y auspiciados por el Ministerio Federal de Educación e Investigación de la República Federal de Alemania (BMBF) y la Comisión de Arqueología para Culturas no Europeas (KAAK) del Instituto Arqueológico Alemán (DAI). Los trabajos de campo y las investigaciones realizadas en el marco del proyecto Palpa-Lucanas han sido debidamente autorizados por el entonces Instituto Nacional de Cultura (INC), hoy Ministerio de Cultura.

Expresamos nuestro agradecimiento a todos los colegas y especialistas, peruanos y alemanes, que participaron en los trabajos de campo (prospección y excavaciones arqueológicas) y en el análisis de los materiales recuperados en los mismos. También queremos hacer extensivo este agradecimiento a todas las personas (personal técnico) de Palpa y Laramate que, de una u otra forma, nos apoyaron en los trabajos de campo y en el ordenamiento de los materiales arqueológicos. Finalmente, agradecemos a la Comunidad Campesina de Laramate, Lucanas, por darnos las facilidades para cumplir con nuestras investigaciones en la zona.

\section{Notas}

1 Estos proyectos se realizaron en el marco de un proyecto más grande denominado Transecta Andina, el cual tiene como uno de sus objetivos principales realizar el estudio de patrones regionales de asentamiento con métodos arqueológicos; así como estudiar con métodos de las ciencias naturales el desarrollo del ambiente, especialmente del clima y del paisaje. En este contexto se analizan las relaciones entre los cambios naturales y los cambios culturales, partiendo de la hipótesis de que los cambios del paleoambiente tenían un efecto significativo en el desarrollo cultural. En este sentido, los valles de Palpa - localizados en una zona intermedia entre la costa y la sierra- presentan las condiciones ideales para investigar la relación entre paleoambiente y desarrollo cultural.

Las investigaciones en el marco de Transecta Andina se realizaron desde 2002 hasta 2011 y fueron financiados por el Ministerio Federal de Educación e Investigación de Alemania (BMBF), como parte del programa «Nuevas Tecnologías y Métodos de las Ciencias Naturales para las Ciencias Sociales (NTG)». Dicho proyecto contó con la cooperación de geógrafos de las Universidades de Heidelberg y Colonia, especialistas para paleogenética de la Universidad de Gotinga y geólogos especializados en el análisis de isótopos de la Colección para Geología y Paleontología del Estado de Baviera en Munich (Bayerischen Staatssammlung für Geologie und Paläontologie in München). Asimismo, participaron arqueólogos peruanos y extranjeros (del Instituto Arqueológico Alemán), quienes realizaron los estudios arqueológicos y analizaron los patrones de asentamiento en esta parte de la vertiente occidental de los Andes, en el sur del Perú.

2 También en la zona yunga, alrededor de los $1600 \mathrm{msnm}$., se han realizado excavaciones en el sector de Collanco, en donde se ha documentado una intensa ocupación relacionada con la época de transición de Paracas a Nasca.

3 Como valles de Palpa se conocen a los oasis aluviales que conforman los ríos Viscas, Palpa, Grande y Santa Cruz, los cuales luego confluyen en uno solo (río Grande) hasta desembocar en 
el Océano Pacífico. Santa Cruz es el único valle que hasta el momento no ha sido incluido en los estudios arqueológicos del Proyecto Nasca-Palpa, pero sí en los estudios del medio ambiente.

${ }^{4}$ Los distritos de Llauta, Laramate y Ocańa se encuentran en la vertiente occidental de los Andes y pertenecen a la Provincia de Lucanas, Ayacucho.

5 Al parecer solo durante el Período Intermedio Tardío, en el contexto de condiciones climáticas favorables y de un posible incremento en el número de habitantes, se construyeron nuevos complejos de terrazas agrícolas en la sierra y especialmente en la zona yunga.

6 Esta época estuvo marcada por la influencia de la cultura Topará en toda la costa sur. Las evidencias registradas en la zona de las cabezadas indican que también la sierra sur estuvo bajo su área de influencia.

7 Los sitios donde se hicieron excavaciones de prueba son: Occoro (PAP-751), Lindero (PAP-808), Tantar Pata (PAP-813), Pichqa Puquio (PAP-846), Suito Orqo (PAP-873), Mallma (PAP-894) y Chilcapuquio (PAP-918). Estos sitios pertenecen a diferentes períodos, así, Suito Orqo y Mallma tienen ocupación Paracas y Nasca; Tantar Pata tiene ocupación Nasca e Ica; Occoro y Chilcapuquio son de filiación Wari; y Pichqa Puquio tiene ocupación Ica, pero posiblemente fue ocupado desde mucho antes.

8 Posteriormente estos recintos fueron seriamente afectados por la deposición de entierros intrusivos durante la ocupación Wari en el sitio. Al parecer, en ese tiempo hubo predilección por ocupar los espacios hundidos como zona de enterramiento.

9 Los trabajos de prospección en la zona yunga, especialmente en el sector de Collanco, en la parte alta del valle de Palpa, nos han permitido registrar numerosos sitios pertenecientes a la época de transición, en varios de los cuales se observan estructuras arquitectónicas parecidas a las de Cutamalla y Huayuncalla. Recientes excavaciones en Collanco (sitio PAP-1077) vienen confirmando que estos sitios también presentan materiales relacionados con la cultura Topará.

${ }^{10}$ En este punto es importante señalar que, curiosamente, además de la obsidiana, que era un recurso procedente de la sierra ubicada al otro lado del altiplano, más específicamente de las canteras de Quispisisa en Huancasancos (Tripcevich y Contreras 2011), en la zona no se han registrado otros materiales - p.e. cerámica- que sugieran mayores contactos con otras poblaciones de la sierra propiamente dicha, lo cual indica que el altiplano andino constituyó una barrera natural que, al menos en este tiempo, limitó los contactos a solo algunos recursos.

\section{REFERENCIAS}

\section{Eitel, B. y B. Mächtle}

2009 Man and environment in the eastern Atacama Desert (southern Peru): Holocene climate changes and their impact on pre-Columbian Cultures, en: M. Reindel y G. Wagner (eds.), New Technologies for Archaeology: Multidisciplinary Investigations in Palpa and Nasca, Peru, 17-37, Natural Science in Archaeology, Springer, Berlín/Heidelberg. https://doi.org/10.1007/978-3-540-87438-6_2

Eitel, B., S. Hecht, B. Mächtle, G. Schukraft, A. Kadereit, G. A. Wagner, B. Kromer, I. Unkel y M. Reindel 2005 Geoarchaeological evidence from desert loess in the Nazca-Palpa region, Southern Peru: Paleoenviromental changes and their impact on Pre-Columbian cultures, Archeometry 47 (1), 137-158. https://doi.org/ 10.1111/j.1475-4754.2005.00193.x

Hecht, N.

2009 Of layers and sherds: A context-based relative chronology of the Nasca style pottery from Palpa, en: M. Reindel y G. Wagner (eds.), New Technologies for Archaeology: Multidisciplinary Investigations in Palpa and Nasca, Peru, 207-230, Natural Science in Archaeology, Springer, Berlín/Heidelberg. 
2013 A relative sequence of Nasca style pottery from Palpa, Peru, tesis de doctorado, Facultad de Artes y Humanidades, Universidad de Bonn. https://doi.org/10.1007/978-3-540-87438-6_13

Isla, J.

2010 Perspectivas sobre el proceso cultural en los valles de Palpa, costa sur del Perú, Arqueología y desarrollo. Experiencias y posibilidades en el Perú, L. Valle (ed.), 15-52, Ediciones SIAN. Trujillo.

Isla, J. y M. Reindel

2017 Palpa and Lucanas: Cultural development under changing climatic conditions on the western slope of the Andes in southern Peru, en: A. Casey (ed.), The Andes: Geography, diversity, and sociocultural impacts, 53-119, Nova Science.

Mächtle, B. y B. Eitel

2013 Fragile landscapes, fragile civilizations-How climate determined societies in the pre-Columbian south Peruvian Andes, Catena 103, 62-73. https://doi.org/10.1016/j.catena.2012.01.012

Massey, S. A.

1986 Sociopolitical change in the upper Ica Valley, B.C. 400 to 400 A.D.: Regional states on the south coast of Peru, tesis de doctorado, Department of Archaeology, University of California, Los Angeles.

Menzel, D.

1971 Estudios arqueológicos en los valles de Ica, Pisco, Chincha y Cañete, Arqueología y Sociedad 6, 1-161.

Menzel, D., J. H. Rowe y L. Dawson

1964 The Paracas pottery of Ica: A study in style and time, University of California Publications in American Archaeology and Ethnology 50, University of California Press, Berkeley.

Peters A. H.

1997 Paracas, Topará and early Nasca: Ethnicity and society on the south central Andean coast, tesis de doctorado, Department of Anthopology, Cornell University, Ithaca.

Reindel, M.

2009 Life at the edge of the desert. Archaeological reconstruction of the settlement history in the valleys of Palpa, Peru, en: M. Reindel y G. Wagner (eds.), New technologies for archaeology, 439-461, Natural Science in Archaeology, Springer, Berlín/Heidelberg. https://doi.org/10.1007/978-3-540-87438-6_25

2010 Archäologische Forschungen der Jahre 2007 und 2008 im Anden-Transekt, Süd-Peru, Zeitschrift für Archäologie Außereuropäischer Kulturen 3, 207-224.

2012 Archäologische forschungen der jahre 2009 und 2010 im Anden-Transekt, Süd-Peru, Zeitschrift für Archäologie Außereuropäischer Kulturen 4, 370-384.

Reindel, M. y J. Isla

2013 Cambio climático y patrones de asentamiento en la vertiente occidental de los Andes del sur del Perú, Diálogo Andino 41, 83-99. https://doi.org/10.4067/s0719-26812013000100006

2017 Nuevo patrón arquitectónico Paracas en Lucanas, sierra sur del Perú, Boletín de Arqueología PUCP 22, 227-254. https://doi.org/10.18800/boletindearqueologiapucp.201701.009

Rowe, J. H.

1960 Nuevos datos relativos a la cronología del estilo Nasca, en: R. Matos (ed.). Antiguo Perú: Espacio y tiempo, 29-45, Editorial Juan Mejía Baca, Lima.

1967 An Interpretation of Radiocarbon Measurements on Archaeological Samples from Peru, en: J. H. Rowe y D. Menzel (eds.), Peruvian archaeology: Selected readings, 16-30, Palo Alto.

Soßna, V.

2015 Climate and settlement in southern Peru. The northern río Grande de Nasca drainage between 1500 BCE and 1532 CE, Forschungen zur Archäologie Außereuropäischer Kulturen, Band 13, Reichert Verlag, Wiesbaden.

Tripcevich, N. y D. Contreras

2011 Quarrying evidence at the Quispisisa obsidian source, Ayacucho, Peru, Latin American Antiquity 22, 121-136. https://doi.org/10.7183/1045-6635.22.1.121 
Unkel, I., B. Kromer, M. Reindel, L. Wacker y G. A. Wagner

2007 A chronology of the pre-Columbian Paracas and Nasca culture in the South Peru based on AMS-14C dating, Radiocarbon 49, 551-564. https://doi.org/10.1017/s0033822200042466

Unkel, I., M. Reindel, H. Gorbahn, J. Isla, B. Kromer y V. Soßna

2012 A comprenhensive numerical chronology for the pre-Columbian cultures of the Palpa valleys, south coast of Peru, Journal of Archaeological Science 39, 2294-2303. https://doi.org/10.1016/j.jas.2012.02.021

Wallace, D.

1985 Paracas in Chincha and Pisco: A reappraisal of the Ocucaje sequence, en: D. P. Kvietok y D. H. Sandweiss (eds.), Recent studies in Andean prehistory and protohistory, 67-94, Cornell University Latin American Studies Program, Ithaca.

1986 The Topará tradition: An overview, en: D. P. Kvietok y D. H. Sandweiss (eds.), Recent studies in Andean prehistory and protohistory, 35-47, Cornell University Latin American Studies Program, Ithaca.

Recepción: 4/VI/2018

Aceptación: 17/VII/2018 